\title{
17-AAG synergizes with Belinostat to exhibit a negative effect on the proliferation and invasion of MDA-MB-231 breast cancer cells
}

\author{
YU ZUO $^{1 *}$, HENG XU $^{2,3^{*}}$, ZHIFENG $\mathrm{CHEN}^{2}$, FENGMIN XIONG $^{1}$, BEI ZHANG $^{2}$, \\ KAIXIAN CHEN $^{2,3}$, HUALIANG JIANG ${ }^{2,3}$, CHENG LUO $^{2,3}$ and HAO ZHANG ${ }^{2,3}$ \\ ${ }^{1}$ Department of Pharmacy, School of Pharmacy, Nanchang University, Nanchang, Jiangxi 330006; \\ ${ }^{2}$ Department of Drug Discovery and Design Center, State Key Laboratory of Drug Research, \\ Shanghai Institute of Materia Medica, Chinese Academy of Sciences, Shanghai 201203; \\ ${ }^{3}$ Department of Pharmacy, University of Chinese Academy of Sciences, Beijing 100049, P.R. China
}

Received June 11, 2019; Accepted January 10, 2020

DOI: $10.3892 /$ or.2020.7563

\begin{abstract}
Breast cancer is one of the most common malignancies that threaten the health of women. Although there are a few chemotherapies for the clinical treatment of breast cancer, these therapies are faced with the problems of drug-resistance and metastasis. Drug combination can help to reduce the adverse side effects of chemotherapies using single drugs, and also help to overcome common drug-resistance during clinical treatment of breast cancer. The present study reported the synergistic effect of the heat shock protein 90 inhibitor 17-AAG and the histone deacetylase 6 inhibitor Belinostat in triple-negative breast cancer (TNBC) MDA-MB-231 cells, by detection of proliferation, apoptosis and cell cycle arrest following treatment with this combination. Subsequently, RNA sequencing (RNA-seq) data was collected and analyzed to investigate the synergistic mechanism of this combination. Based on the Kyoto Encyclopedia of Genes and Genomes (KEGG) signaling pathways revealed by RNA-seq data analysis, a wound-healing assay was used to investigate the effect of this combination on the migration of MDA-MB-231 cells. Compared with treatment with 17-AAG or Belinostat alone, both the viability inhibition and apoptosis rate of MDA-MB-231 cells were significantly enhanced in the combination group. The combination index values were $<1$ in three concentration groups. Revealed by the
\end{abstract}

Correspondence to: Dr Cheng Luo or Dr Hao Zhang, Department of Drug Discovery and Design Center, State Key Laboratory of Drug Research, Shanghai Institute of Materia Medica, Chinese Academy of Sciences, $555 \mathrm{Zu}$ Chongzhi Road, Shanghai 201203, P.R. China

E-mail: cluo@simm.ac.cn

E-mail:hao_cadd@simm.ac.cn

${ }^{*}$ Contributed equally

Key words: triple-negative breast cancer, heat shock protein 90 inhibitor, histone deacetylase 6 inhibitor, synergistic
RNA-seq data analysis, the most significantly enriched KEGG pathways in the combination group were closely associated with cell migration. Based on these findings, the anti-migration effect of this combination was investigated. It was revealed that the migration of MDA-MB-231 cells was significantly suppressed in the combination group compared with in the groups treated with 17-AAG or Belinostat alone. In terms of specific genes, the mRNA expression levels of TEA domain family proteins were significantly decreased in the combination group, whereas the phosphorylation of YY1 associated protein 1 and modulator of VRAC current 1 was significantly enhanced in the combination group. These alterations may help to explain the anti-migration effect of this combination. Belinostat has already been approved as a treatment for T-cell lymphoma and 17-AAG is undergoing clinical trials. These findings could provide a beneficial reference for the clinical treatment of patients with TNBC.

\section{Introduction}

As one of the most common types of cancer that threat the health of women worldwide, breast cancer originates from breast epidermal tissues and has a high mortality rate (1). The difficulty in clinical treatment of breast cancer has mainly been attributed to two aspects. First, breast cancer exhibits a higher risk of metastasizing to distant vital organs of the body compared with other solid tumors (2). Second, the heterogeneity of breast cancer limits the development of targeted therapy (3). According to the expression of the estrogen receptor (ER), progesterone receptor (PR) and HER2, breast cancer can be classified into two categories (4). For the first category, at least one of these receptors is positive. Selective ER inhibitors, such as Tamoxifen, and PR inhibitors, such as Mifepristone, are widely used in the clinical treatment of ER-positive and PR-positive breast cancer (5). For the clinical treatment of HER2-positive breast cancer, the potent monoclonal HER2 antibody Herceptin and its derivatives are the most efficient therapy (6). Combinations of Herceptin with small-molecular drugs for the treatment of HER2-positive metastatic breast 
cancer have entered clinical trials, suggesting the advantages of combined medication (6).

For the second category, triple-negative breast cancer (TNBC) lacks the expression of ER, PR or HER2. According to statistics from 2010, TNBC comprises $12-20 \%$ of breast cancer cases and the percentage is rising (7). Since TNBC is the most malignant breast cancer type and prone to metastasis and recurrence, common therapies usually fail to achieve satisfactory treatment effects (8). Therefore, seeking novel therapeutic targets and agents for the treatment of TNBC is challenging and urgent. Usually, molecular targeted therapy aims at retrieving aberrant signaling transduction by selective inhibitors (9). Considering the heterogeneity of TNBC, various categories of pathway inhibitors are used in clinical treatment (10). However, a large proportion of patients with TNBC receiving monotherapy encounter drug-resistance, metastasis and recurrence (11). Therefore, combined medications using inhibitors targeting different signaling pathways are emerging for the clinical treatment of TNBC (12). Compared with traditional monotherapy, combined therapies usually are associated with enhanced efficacy and reduced risks of recurrence (13-15).

As a molecular chaperone, heat shock protein 90 (HSP90) aids various client proteins to fold into correct conformation (16). However, the dysfunction of HSP90 leads to the misfolding and degradation of its client proteins. As a derivative of the antibiotic Geldanamycin, the HSP90 inhibitor 17-AAG (Tanespimycin) exhibits improved selectivity (17). The binding affinity of 17-AAG to the HSP90 protein in tumor cells is 100 times higher than to HSP90 protein in normal cells (18). 17-AAG exhibits broad-spectrum antitumor activity against various types of cancer in pre-clinical studies (19-21). It is worth noting that HER2 is one of the client proteins of HSP90, and clinical trial results have revealed that HSP90 inhibitor 17-AAG treatment is beneficial in HER2-positive breast cancer (22). A previous study has demonstrated that the combination of 17-AAG with Herceptin effectively overcomes the drug-resistance of Herceptin monotherapy (23). As a previously identified biomarker for TNBC, the inhibitors of HSP90 may be beneficial to the combined medications of breast cancer $(24,25)$.

Dysfunction of histone acetylation is frequently observed in various types of cancer, including breast cancer (26-28). Histone acetyltransferase (HAT) and histone deacetylase (HDAC) are responsible for the regulation of histone acetylation $(29,30)$. HAT and HDAC are important epigenetic targets for the development of antitumor agents (31). Overwhelming evidence has demonstrated that HDAC inhibitors, including HDAC6 inhibitors, are promising for the combined treatment of TNBC (32-35). Besides the acetylation of histone H4, HDAC6 also regulates the acetylation of other proteins, including HSP90 and $\alpha$-tubulin (36). Additionally, a previous study has revealed that the overexpression of HDAC6 is closely associated with the metastasis and poor prognosis of patients with breast cancer (37). As one of the client proteins of HSP90, HDAC6 regulates the acetylation of HSP90 reversely (38). Acetylated HSP90 protein loses most of the chaperone activity, and the activity of its client proteins will abrogate afterwards (39). As a HDAC inhibitor, Belinostat exhibits potent inhibitory effects on HDAC6 in vitro, with an $\mathrm{IC}_{50}$ value of
$82 \mathrm{nM}(40,41)$. Previous studies have indicated that Belinostat is a beneficial choice for combined therapy of both blood and solid tumors $(42,43)$. Previous studies in other cancer types have indicated that the combination of HSP90 inhibitor and HDAC6 inhibitor exhibits more benefits than administration alone (44-46). Several HSP90 or HDAC combination therapies have been investigated in clinical trials $(12,47)$; however, most of them investigated combination therapies with chemotherapeutic drugs, such as cisplatin or paclitaxel. The primary clinical trial data indicated that TNBC may show response to HSP90 or HDAC combination therapy, but in combination with chemotherapeutic drugs unchangeable side effects caused by chemotherapeutic drugs remain. In TNBC, combination therapies with chemotherapeutic drugs exhibit high risk (48) and occasionally have no benefit compared with single drug treatment $(49,50)$. Therefore, combined with chemotherapeutic drugs, HSP90 inhibitor or HDAC inhibitor may show the same high risk as single drug treatment in TNBC. Considering the internal mechanism of HDAC6 and HSP90, it was proposed that the HDAC6-HSP90 axis may show benefits in TNBC. If the HDAC6-HSP90 axis could show a combination effect, in further clinical trials, researchers may have the choice to avoid using chemotherapeutic drugs. The present study revealed that the HSP90 inhibitor 17-AAG synergizes with the HDAC6 inhibitor Belinostat in MDA-MB-231 cells, which may provide a beneficial reference for the clinical treatment of TNBC.

\section{Materials and methods}

Cell lines and compounds. The ER-positive breast cancer MCF-7 cell line, TNBC MDA-MB-231 and BT549 cell lines, and a normal human mammary epithelial MCF-10A cell line were purchased from the American Type Culture Collection. All cell lines were cultured in a cell incubator (model no. thermo3111; Thermo Fisher Scientific, Inc.) at $37^{\circ} \mathrm{C}$ with $5 \% \mathrm{CO}_{2}$. The MDA-MB-231 and MCF-7 cells were cultured in DMEM (cat. no. L110KJ; BasalMedia, Inc.) supplemented with $10 \%$ fetal bovine serum (FBS; cat. no. 16000-044; Gibco; Thermo Fisher Scientific, Inc.) BT549 cells were cultured in DMEM supplemented with $10 \% \mathrm{FBS}$ and $0.023 \mathrm{U} / \mathrm{ml}$ insulin. MCF-10A cells were cultured in DMEM/F12 (cat. no. L310KJ; BasalMedia, Inc.) supplemented with 5\% donor horse serum (cat. no. 26050088; Gibco; Thermo Fisher Scientific, Inc.) and certain additives (20 ng/ml EGF, $10 \mu \mathrm{g} / \mathrm{ml}$ insulin and $10 \mathrm{ng} / \mathrm{ml}$ cholera toxin). Belinostat (HDAC6 inhibitor) and 17-AAG (HSP90 inhibitor) were purchased from Target molecule Corp. and prepared in DMSO as $50 \mathrm{mM}$ stock solutions. The solutions were diluted in cell culture medium immediately prior to use.

Cell viability assay and combination studies. Four different cell lines (MDA-MB-231, BT549, MCF-7 and MCF-10A) were seeded in 96-well flat bottom plates at a density of 3,000 cells/well and treated with $200 \mu \mathrm{M}$ to $0.78 \mathrm{nM}$ (double gradient dilution) $17-\mathrm{AAG}$ or Belinostat at $37^{\circ} \mathrm{C}$ in triplicate $12 \mathrm{~h}$ later. The viability of cells was measured using the CellTiter-Glo Luminescent Cell Viability assay (Promega Corporation) at $72 \mathrm{~h}$ after treatment. The optical density of each well was recorded using a microplate reader (PerkinElmer Envision multimode plate reader; PerkinElmer, Inc.). A range 
of drug concentrations was added at their fixed ratio based on their respective individual $\mathrm{IC}_{50}$ values at $72 \mathrm{~h}$ (51). Using the CompuSyn software (52) (CompuSyn v1.0; ComboSyn, Inc.), combination indexes (CIs) were calculated according to the cell viability at corresponding concentrations. Briefly, the $\mathrm{CI}$ value indicates the interaction of co-administrated compounds: $\mathrm{CI}<1$ indicates synergism effect, $\mathrm{CI}=1$ indicates additive effect and $\mathrm{CI}>1$ indicates antagonism effect (53).

Apoptosis and cell cycle analysis. For the apoptosis analysis, cells were seeded in 6-well flat bottom plates at a density of $1.5 \times 10^{5}$ cells/well and treated with single 17-AAG (0.5 and $1.0 \mu \mathrm{M})$, single Belinostat $(0.1$ and $0.2 \mu \mathrm{M})$, or the combination of $17-\mathrm{AAG}$ and Belinostat at $37^{\circ} \mathrm{C}$ for $12 \mathrm{~h}$. After incubation for $72 \mathrm{~h}$, cells were harvested in iced PBS buffer. Apoptosis was evaluated using the Annexin V-FITC Apoptosis Detection kit (Vazyme Biotech Co., Ltd.). Briefly, collected cells were re-suspended in $100 \mu \mathrm{l}$ binding buffer and incubated with $5 \mu \mathrm{l}$ propidium iodide (PI) and $5 \mu \mathrm{l}$ Annexin V-FITC for $15 \mathrm{~min}$ in the dark at room temperature. Before analyzing apoptosis percentage using the FACSCalibur flow cytometry system (BD Biosciences), $400 \mu \mathrm{l}$ binding buffer was added to the samples to stop the staining procedure. The apoptosis data were analyzed using FlowJo ${ }^{\text {TM }}$ software (FlowJo 7.6.1; BD Biosciences), with $\geq 10,000$ cells for each sample. For the cell cycle analysis by PI staining, cells were seeded and harvested as for the apoptosis assay. Each sample was fixed and re-suspended in $1 \mathrm{ml}$ iced $70 \%$ ethanol at $-20^{\circ} \mathrm{C}$ overnight. After washing twice with iced PBS buffer, samples were stained with PI in the dark at room temperature for $30 \mathrm{~min}$. The PI stain was included in the Cell Cycle and Apoptosis Analysis kit (Yeasen). Subsequently, cell cycle analysis was performed using FACScan flow cytometry (FACS Canto II; BD Biosciences) by red fluorescence at an excitation wavelength of $488 \mathrm{~nm}$, and the data were analyzed using ModFit software (ModFit LT v3.3; BD Biosciences).

Reverse transcription-quantitative PCR (RT-qPCR). Total RNA was extracted from MDA-MB-231 cells using the RNA Isolation kit (Beyotime Institute of Biotechnology). Each sample of $300 \mathrm{ng}$ total RNA was reverse transcribed to cDNA using the HiScript II Q RT SuperMix for qPCR kit (Vazyme Biotech Co., Ltd.). The reverse transcription temperature protocol was as follows: $50^{\circ} \mathrm{C}$ for $15 \mathrm{~min}$, followed by $80^{\circ} \mathrm{C}$ for $5 \mathrm{sec}$. The qPCR procedures were performed on the ViiA 7 Real-Time PCR system (Applied Biosystems; Thermo Fisher Scientific, Inc.) using the ChamQ SYBR qPCR Master Mix (Low ROX Premixed) kit (Vazyme Biotech Co., Ltd.). The thermocycling program for the RT-qPCR reactions was as follow: Pre-denaturation at $95^{\circ} \mathrm{C}$ for $10 \mathrm{~min}, 40$ cycles of denaturation at $95^{\circ} \mathrm{C}$ for $15 \mathrm{sec}$ and annealing at $60^{\circ} \mathrm{C}$ for $30 \mathrm{sec}$, followed by extension at $72^{\circ} \mathrm{C}$ for $1 \mathrm{~min}$. Subsequently, the expression values of mRNA were calculated using the $2^{-\Delta \Delta \mathrm{Cq}}$ method (54), with GAPDH as a reference for normalization, and represented as fold change. Primers were synthesized by Sangon Biotech Co., Ltd. and are listed in Table I.

Western blotting. Cells were seeded in 6-well flat plates and split in 1X SDS sample loading buffer $(250 \mathrm{mM}$ Tris $\mathrm{HCl}$ pH $6.8,10 \%$ SDS, 30\% glycerol, 5\% $\beta$-mercaptoethanol
Table I. List of primers used for quantitative PCR.

Primer Sequence (5'-3')

HSP90AA1-Forward HSP90AA1-Reverse HSP90AB1-Forward HSP90AB1-Reverse GAPDH-Forward GAPDH-Reverse TEAD1-Forward TEAD1-Reverse TEAD2-Forward TEAD2-Reverse TEAD3-Forward TEAD3-Reverse TEAD4-Forward TEAD4-Reverse YAP-Forward YAP-Reverse TAZ-Forward TAZ-Reverse EGFR-Forward EGFR-Reverse COX5B-Forward COX5B-Reverse COX7C-Forward COX7C-Reverse UBA52-Forward UBA52-Reverse NFKBIE-Forward NFKBIE-Reverse GADD45A-Forward GADD45A-Reverse
GCTTGACCAATGACTGGGAAG AGCTCCTCACAGTTATCCATGA CATCTCCATGATTGGGCAGTT CTTTGACCCGCCTCTCTTCTA AGGTCGGTGTGAACGGATTTG GGGGTCGTTGATGGCAACA ATGCCAACCATTCTTACAGTGAC ACAGTTCCTTTAAGCCACCTTTC CTTCGTGGAACCGCCAGAT GGAGGCCACCCTTTTTCTCA GCTCCTGGAGTATTCAGCCTT GTCGGCCCAGAACTTGACAA GGACACTACTCTTACCGCATCC TCAAAGACATAGGCAATGCACA CGCTCTTCAACGCCGTCA AGTACTGGCCTGTCGGGAGT CACCGTGTCCAATCACCAGTC TCCAACGCATCAACTTCAGGT AGGCACGAGTAACAAGCTCAC ATGAGGACATAACCAGCCACC ATCTGGAGGTGGTGTTCCCA TCCAGTCCCTTCTTTGCAGC GGGCCCTGGGAAGAATTTGC GGAAGGGTGTAGCAAATGCAGA GTCGTGCGGACGCAAACAT TCTCAATGGTGTCACTGGGC AAACTGGCAAGGTCTGGCTT GTCTTACCACTGGTGCCCTC GCAGAAGACCGAAAGCGACC TGATGTCGTTCTCGCAGCAA

and $0.02 \%$ bromophenol blue). Protein concentrations were determined using the BCA Protein assay (Thermo Fisher Scientific, Inc.). Samples (25 $\mu \mathrm{g} / \mathrm{lane})$ were resolved by 6 , 10 or $12 \%$ SDS-PAGE and transferred to $0.22-\mu \mathrm{m}$ nitrocellulose membranes. Following blocking with $5 \%$ milk at room temperature for $1 \mathrm{~h}$, the nitrocellulose membranes were washed four times for 15 min with TBS with $0.1 \%$ Tween-20 (TBST) buffer and incubated with primary antibodies (dilution, 1:1,000) at $4^{\circ} \mathrm{C}$ overnight. Subsequently, the membranes were washed four times with TBST buffer and incubated with horseradish peroxidase (HRP)-conjugated Goat Anti-Mouse lgG (cat. no. D110087; Sangon Biotech Co., Ltd.) and HRP-conjugated Goat Anti-Rabbit $\lg G$ (cat. no. D110058; Sangon Biotech Co., Ltd.) secondary antibodies (dilution, 1:10,000; BBI Life Sciences Corporation) for $1 \mathrm{~h}$ at room temperature. The bands were visualized using an enhanced chemiluminescence kit (Thermo Fisher Scientific, Inc.) with a ChemiScope 3400 mini imaging system (Clinx Science Instrument Co., Ltd.). Densitometry was performed for each group using ImageJ $1.50 \mathrm{~b}$ software (National Institutes of Health). All primary antibodies used are listed in Table II. 
Table II. List of primary antibodies used for western blotting.

\begin{tabular}{llc}
\hline Name & \multicolumn{1}{c}{ Supplier } & Cat. no. \\
\hline HDAC6 & Beyotime Institute of Biotechnology & AH395 \\
$\alpha$-tubulin $(11 \mathrm{H} 10)$ & Cell Signaling Technology, Inc. & $2125 \mathrm{~S}$ \\
Ac- $\alpha$-tubulin & Cell Signaling Technology, Inc. & $5335 \mathrm{~S}$ \\
HSP90 & Cell Signaling Technology, Inc. \\
Ac-k & Cell Signaling Technology, Inc. \\
Cleaved-parp & Cell Signaling Technology, Inc. \\
Cleaved-caspase3 & Cell Signaling Technology, Inc. \\
CDK1 & Absin & 4877T \\
P-CDK1 & Cell Signaling Technology, Inc. \\
cyclin B1 & Cell Signaling Technology, Inc. \\
P-MLC & Invitrogen; Thermo Fisher Scientific, Inc. \\
MLC2 & Cell Signaling Technology, Inc. \\
YAP & Cell Signaling Technology, Inc. \\
P-YAP & Cell Signaling Technology, Inc. \\
TEAD1 & Cell Signaling Technology, Inc. \\
TEAD2 & ProteinTech Group, Inc. \\
TEAD3 & Cell Signaling Technology, Inc. \\
TEAD4 & Abcam & abs135544 \\
& & $2461 T$ \\
& $4138 S$ \\
\end{tabular}

RNA-sequencing (RNA-seq) data collection and analysis. To characterize the genomic impact of single and combined compound treatment, RNA-seq data was collected using $1.5 \times 10^{5}$ MDA-MB-231 cells treated with DMSO as a control, 17-AAG $(1.0 \mu \mathrm{M})$, Belinostat $(0.2 \mu \mathrm{M})$ and the combination of 17-AAG and Belinostat at $37^{\circ} \mathrm{C}$ for $72 \mathrm{~h}$. After $24 \mathrm{~h}$, total RNA was isolated and purified using DNaseI (Takara Bio, Inc.) and Dynabeads Oligo (dT) 25 (Thermo Fisher Scientific, Inc.). Subsequently, purified RNA (100 ng) was used for cDNA library construction, using the NEBNext Ultra $^{\mathrm{TM}}$ RNA Library Prep kit for Illumina (cat. no. E7530L; New England BioLabs, Inc.). Sequencing data was collected on an Illumina HiSeq 2500 instrument. Subsequently, paired-end reads were processed using the Tophat 2 v2.1.1 software package (55), with the GRCh38/hg18 Ensembl transcript set as a reference. Following transcript assembly using the Cufflinks v2.2.1 software package (56), differentially expressed genes ( $\log _{2}$ fold-changel $>0.5$ and $\mathrm{P}<0.05$ ) were identified using Cuffdiff 2 (57). From the list of differentially expressed genes, each gene was checked in the Gene database of the National Center for Biotechnology Information (https://www.ncbi.nlm.nih.gov/gene/). According to the relevant abstract description of genes in NCBI, only the most migration-related or metastasis-related genes were selected for the final heatmap. The Kyoto Encyclopedia of Genes and Genomes (KEGG) database (http://www.kegg.jp/) was used for pathway analysis. Using the GeneAnswers v3.0 package (58) of the Bioconductor project, the P-values of involved KEGG pathways were calculated with a threshold value of 0.1 , based on all differentially expressed genes. Finally, the heatmap and pathways histogram were plotted using the ggplot2 v2.1.0 package in R (http:/www.rdocumentation.org/packages/gglot2/versions/2.1.0). The raw sequencing data and processed expression tables have been deposited to the Gene Expression Omnibus (GEO) database (http://www.ncbi.nlm.nih.gov/geo/; accession no. GSE129944).

Detection of reactive oxygen species (ROS). MDA-MB-231 cells were seeded in 6-well plates at a density of $7.5 \times 10^{4}$ cells $/ \mathrm{ml}$ and permitted to adhere overnight. After cells were treated with $0.2 \mu \mathrm{M}$ Belinostat, $1 \mu \mathrm{M}$ 17-AAG or the combination at $37^{\circ} \mathrm{C}$ for 3 days, cells were stained with $1 \mu \mathrm{M}$ DCFH-DA for $30 \mathrm{~min}$ in the dark at $37^{\circ} \mathrm{C}$. Subsequently, cells were washed three times with PBS and subjected to FACScan flow cytometry (FACS Canto II; BD Biosciences). Green fluorescence FITC (FL1) was detected at $488 \mathrm{~nm}$ (excitation wavelength) and $530 \mathrm{~nm}$ (emission wavelength). FlowJo ${ }^{\mathrm{TM}}$ software (FlowJo 7.6.1; BD Biosciences) was used to calculate and analyze the data. Fluorescence microscopy (magnification, x40) was used to capture images with fixed exposure time.

Wound healing assay. For the wound healing assay, coordinates were marked on the 35-mm dish, and MDA-MB-231 cells were inoculated at a density of $1.5 \times 10^{6}$ cells/well. When the confluence was $\sim 100 \%$, cells were rinsed twice with PBS, and serum-free DMEM was added for cell starvation. After cells were starved for $24 \mathrm{~h}$, three marks were scratched on the dish covered with cells with a $200-\mu 1$ pipette tip. Subsequently, the dish was washed twice with PBS to remove cell debris, and serum-free DMEM containing $0.2 \mu \mathrm{M}$ Belinostat, $1 \mu \mathrm{M} 17-\mathrm{AAG}$ or the combination of both was added after scratching. Images were captured under an inverted light microscope (magnification, $\mathrm{x} 40$ ) at different time points. The cell scratch area at each coordinate point was recorded. The relative migration area was calculated, and average values were taken for comparison. The area of cells was calculated for each group using ImageJ $1.50 \mathrm{~b}$ software (National Institutes of Health) The wound-closing procedure was observed for $36 \mathrm{~h}$, and images were captured at 0 and $36 \mathrm{~h}$, respectively. 
Cell migration and invasion assays. For the cell migration assay, serum-free medium was added to the Transwell (cat. no. 353097; Corning Inc.) and outer chamber, and the membrane of the chamber was hydrated $1 \mathrm{~h}$ later. A total of $1.5 \times 10^{5}$ MDA-MB-231 cells were plated into $35-\mathrm{mm}$ dishes containing serum-free DMEM. Following starvation at $37^{\circ} \mathrm{C}$ for $12-24 \mathrm{~h}$ to further remove the effect of serum, cells were digested, centrifuged at $300 \mathrm{x} \mathrm{g}$ at room temperature for 5 min and the media were discarded. Subsequently, cells were washed once or twice with PBS, and re-suspended with the serum-free culture medium containing $0.1 \%$ BSA (Sigma-Aldrich; Merck KGaA) The density of cells was adjusted to $1 \times 10^{6}$ cells $/ \mathrm{ml}$. A total of $1.0 \times 10^{5}$ MDA-MB-231 cells were added to the upper Transwell chamber containing $0.2 \mu \mathrm{M}$ Belinostat, $1 \mu \mathrm{M}$ 17-AAG or combination of both, and $600 \mu \mathrm{l}$ DMEM containing 10\% FBS was added to the lower chamber of the 24-well plate. Placed on a 24 -well plate, the surface of the Transwell compartment membrane was carefully observed for bubble formation. Following incubation at $37^{\circ} \mathrm{C}$ for $24 \mathrm{~h}$, Transwell cells were washed twice with PBS, and a cotton swab was used to remove cells from the upper chamber. Subsequently, cells were fixed with $90 \%$ ethanol at room temperature for $15 \mathrm{~min}$, and the membrane was dried and stained with $0.1 \%$ crystal violet at room temperature for 30 min. Finally, the Transwell membrane was cut off and placed on a glass slide for microscopic observation, and six locations were randomly selected for imaging by means of an inverted light microscope (magnification, $x 40$ ). The number of cells was calculated for each group using Image J $1.50 \mathrm{~b}$ software (National Institutes of Health). For the cell invasion assay, the procedure was similar to the cell migration assay, except that the Transwell membranes were pre-coated with $50 \mathrm{mg} / \mathrm{ml}$ Matrigel (BD Biosciences) at $37^{\circ} \mathrm{C}$ for $1 \mathrm{~h}$.

Small interfering RNA (siRNA) transfection. TEA domain family members (TEADs) siRNAs were synthesized by Shanghai GenePharma Co., Ltd. Cells were seeded in a 6 -well plate to be $60-80 \%$ confluent. A total of $1.5 \mu \mathrm{l}$ siRNA $(20 \mu \mathrm{M})$ and $9 \mu \mathrm{l}$ Lipofectamine ${ }^{\circledR}$ RNAiMAX reagent (cat. no. 13778150; Invitrogen; Thermo Fisher Scientific, Inc.) were mixed with $150 \mu$ l Opti MEM medium (cat. no. 31985070; Gibco; Thermo Fisher Scientific, Inc.). The final concentration of siRNAs was $25 \mathrm{pM}$. Next, diluted siRNA was added to diluted Lipofectamine RNAiMAX reagent and cultured 5 min at room temperature. siRNA-lipid complex was added to cells for $6-8 \mathrm{~h}$ at $37^{\circ} \mathrm{C}$ and cells were re-cultured in complete medium for $48 \mathrm{~h}$ at $37^{\circ} \mathrm{C}$. Subsequent experiments were performed after the cells were transfected for $48 \mathrm{~h}$. Control siRNA was used as a negative control. siRNAs used for siRNA transfection are listed in Table III.

Statistical analysis. All data are presented as the mean \pm SEM. All experiments, including western blotting, were performed in duplicate or triplicate. Western blotting semi-quantification was implemented by ImageJ 1.50 b (National Institutes of Health) Statistical analyses were carried out using the GraphPad 5.0 software (GraphPad Software, Inc.). Comparisons between two groups were implemented using the unpaired two-tailed Student's t-test. Comparisons of three groups were executed by multiple t-tests with the Holm-Sidak method, as recommended
Table III. List of siRNAs used for siRNA transfection.

Gene name $\quad$ Sequence (5'-3')

$\begin{array}{ll}\text { TEAD1-homo-1018 } & \text { CCACUGCCAUUCAUAACAATT } \\ \text { TEAD1-homo-1826 } & \text { CAUGGCCUGUGUGUUUGAAT } \\ \text { TEAD2-homo-667 } & \text { CCAGAUGUGAAGCCAUUCUTT } \\ \text { TEAD2-homo-1283 } & \text { GCGCCAGAUCUAUGACAAATT } \\ \text { TEAD3-homo-1040 } & \text { GCGCCAGAUCUAUGACAAATT } \\ \text { TEAD3-homo-1510 } & \text { CCCAGCACCAUGUCUACAATT } \\ \text { TEAD4-homo-1284 } & \text { CCACGAAGGUCUGCUCUUUTT } \\ \text { TEAD4-homo-1507 } & \text { GGAGACCUUGCUGUGCAUUTT } \\ \text { NC } & \text { UUCUCCGAACGUGUCACGUTT }\end{array}$

siRNA, small interfering RNA; TEAD, TEA domain family member; $\mathrm{NC}$, negative control.

by the GraphPad software. $\mathrm{P}<0.05$ was considered to indicate a statistically significant difference.

\section{Results}

TNBC cell lines maintain relatively high expression levels of HSP90 and HDAC6. To confirm whether TNBC cell lines have relatively high expression levels of both HSP90 and HDAC6, the mRNA expression and protein abundance levels of HSP90 and HDAC6 were detected in four breast cell lines. It was identified that the mRNA expression levels of HDAC6 were upregulated in TNBC cell lines, but for HSP90, the two subunits, HSP90AA1 and HSP90AB1, exhibited no significant differences across the four cell lines examined (Fig. 1A and B). Based on the protein expression levels presented in Fig. 1C, HSP90 exhibited similar abundance in the cell lines, except in BT549 where its expression was slightly decreased. Statistical analysis demonstrated that HSP90 protein levels did not no differ across the four cell lines (Fig. 1D). However, HDAC6 expression was upregulated in TNBC cells which was consistent with the results for mRNA expression. Overall, the results indicated that TNBC cell lines maintain relatively high expression levels of HDAC6, whereas the expression levels of HSP90 were almost consistent. It may be speculated that the combination of HSP90 inhibitor and HDAC6 inhibitor could have an improved therapeutic effect in TNBC cell lines. As aforementioned, reciprocal effects exist between HSP90 and HDAC6 (38). The present study aimed to determine whether combined treatment with HSP90 inhibitor and HDAC6 inhibitor may achieve enhanced efficacy compared with treatment with either inhibitor alone.

Synergistic effects exist between HSP90 inhibitor 17-AAG and HDAC6 inhibitor Belinostat in MDA-MB-231 cells. To determine whether synergistic effects exist between the HSP90 inhibitor 17-AAG and HDAC6 inhibitor Belinostat, the $\mathrm{IC}_{50}$ value and cell viability of these two drugs were measured to generate a concentration-inhibition matrix for combined treatment (Fig. 2A and B). Based on a previous study (51), the effects of the combination were calculated using the CI, because it has been recognized that the fixed dose ratio of two drugs based on 

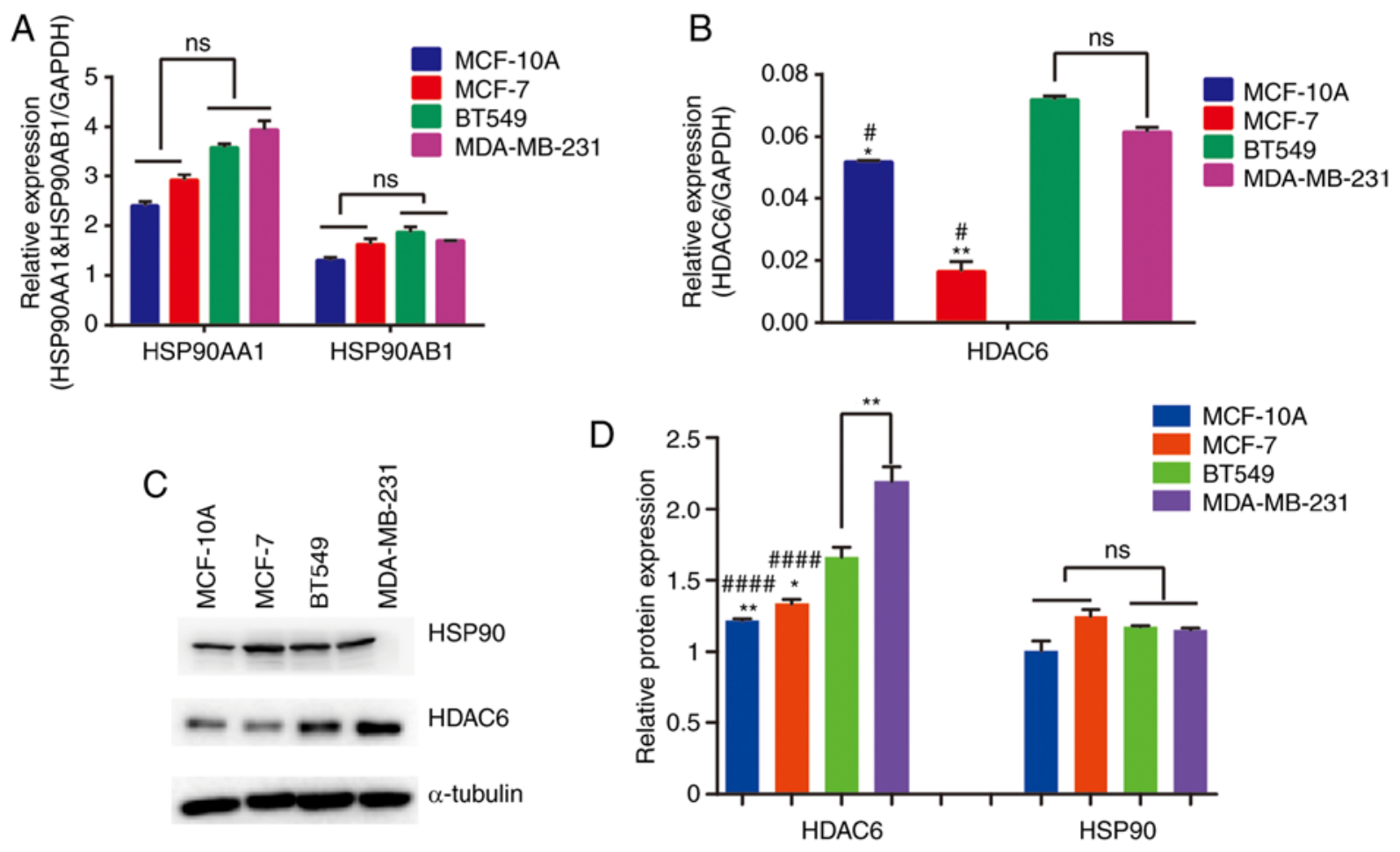

Figure 1. Relatively high expression of HSP90 and HDAC6 in TNBC cells. (A) mRNA expression levels of HSP90 subunits (HSP90AA1 and HSP90AB1) exhibited no differences across the four cell lines. (B) mRNA expression levels of HDAC6 were higher in TNBC cell lines. (C) Protein abundance of HDAC6 and HSP90 in the four cell lines. (D) Protein semi-quantification of HDAC6 and HSP90 in breast cancer cell lines and the normal breast MCF-10 cell line. Data are presented as the mean \pm SEM. ${ }^{*} \mathrm{P}<0.05,{ }^{* *} \mathrm{P}<0.01$ vs. BT549; ${ }^{*} \mathrm{P}<0.05,{ }^{\# \# \#} \mathrm{P}<0.0001$ vs. MDA-MB-231. TNBC, triple-negative breast cancer; HDAC6, histone deacetylase 6; HSP90, heat shock protein 90; ns, not significant.

individual $\mathrm{IC}_{50}$ values can achieve a rational CI. MDA-MB-231, MCF-10A, MCF-7 and BT549 cells were treated with three different concentrations of 17-AAG and Belinostat. The effective concentration ratio between 17-AAG and Belinostat was $\sim 5,0.023,1.8$ and 0.0008, respectively (Fig. 2A and B). In MCF-10A and BT549 cells, the CI values were $>1$ at three groups of concentrations selected according to effective concentration ratio between 17-AAG and Belinostat (Fig. 2C). This indicated that the two drugs have an antagonistic effect. The antagonistic effect may be caused by high sensitivity to 17-AAG of MCF-10A and BT549 cells. BT549 cells exhibited higher sensitivity to 17-AAG than Belinostat (Fig. 2A and B), which could not be observed and concluded from Fig. 1. The mechanism of the dominant effect of 17-AAG in BT549 cells requires further study; however, the present study aimed to explore the combination effect of the HSP90-HDAC6 axis. The $\mathrm{CI}$ values were $<1$ at different concentrations in MDA-MB-231 and MCF7 cells. However, considering the $\mathrm{IC}_{50}$ value of 17-AAG in MCF-7, it was revealed that the difference in cell inhibition rate was not obvious at the near drug concentration (Fig. 2C). Therefore, when setting the fixed molar ratio of the two drugs, the selected three concentration points would lead to a Fa value higher than that of MDA-MB-231. These results indicated that 17-AAG and Belinostat exhibited the best synergistic effect in MDA-MB-231 cells compared with in the other three breast cell lines. Three concentration groups in MDA-MB-231 cells were established for 17-AAG and Belinostat, including $0.50 \mu \mathrm{M}$ 17-AAG and $0.10 \mu \mathrm{M}$ Belinostat, $0.80 \mu \mathrm{M}$ 17-AAG and $0.16 \mu \mathrm{M}$ Belinostat, and $1.00 \mu \mathrm{M} 17-\mathrm{AAG}$ and $0.20 \mu \mathrm{M}$ Belinostat (Fig. 2D).
Combination of 17-AAG and Belinostat leads to enhanced cell cycle arrest and apoptosis in MDA-MB-231 cells. In addition to combination index, the combination of 17-AAG and Belinostat also led to enhanced cell cycle arrest and apoptosis in MDA-MB-231 cells. Two combination groups with low CI values $(0.1 \mu \mathrm{M}$ Belinostat with $0.5 \mu \mathrm{M}$ 17-AAG, and $0.2 \mu \mathrm{M}$ Belinostat with $1.0 \mu \mathrm{M} 17-\mathrm{AAG})$ were selected to treat MDA-MB-231 cells for 3 days. The relative apoptosis rate was not significantly increased in cells treated with 17-AAG or Belinostat (Fig. 3A and C). The combination of 17-AAG and Belinostat led to a marked increase in apoptosis, and the total apoptosis rate increased with the elevation of concentrations (Fig. 3A and C). Additionally, a higher proportion of cells were arrested in the $\mathrm{G}_{2}$ phase following the combined treatment with 17-AAG and Belinostat compared with the single treatment of 17-AAG or Belinostat alone (Fig. 3B), and the rate of $\mathrm{G}_{2}$ phase arrest in the combined treatment group was higher than that in the single treatment groups (Fig. 3D). Consistent with the flow cytometry results, western blotting results demonstrated that the levels of cleaved poly (ADP-ribose) polymerase and caspase 3 were upregulated in the combination group. In addition, the protein abundance of CDK1 phosphorylation (p-CDK1) was upregulated in the combination group and in the single 17-AAG $(1 \mu \mathrm{M})$ group, indicating increased inactivation of CDK1. Furthermore, the protein abundance of cyclin B1 was downregulated in the combination group, indicating an increased proportion of $\mathrm{G}_{2} / \mathrm{M}$ phase arrest.

Reciprocal interactions between Belinostat and HSP90, and 17-AAG and HDAC6. According to a previous study (59), 
A

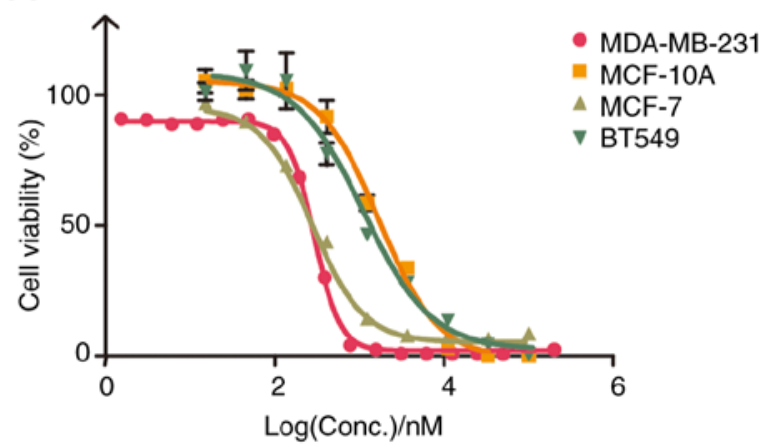

MDA-MB-231

MCF-10A

MCF-7

C

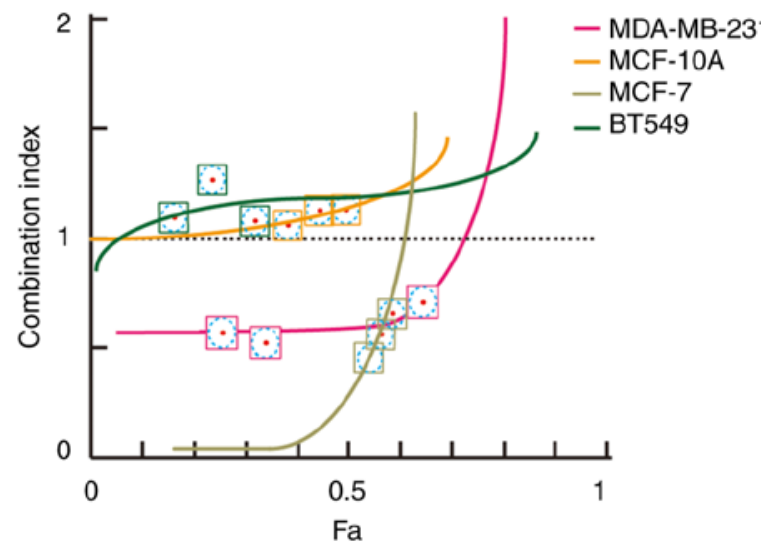

IC50=292.9 nM

$\mathrm{IC} 50=1.755 \mu \mathrm{M}$

IC $50=300 \mathrm{nM}$

IC50 $=1.28 \mu \mathrm{M}$
B

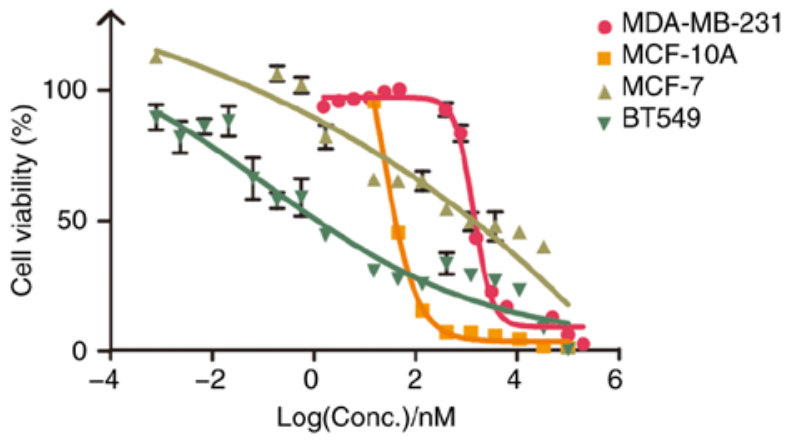

$\begin{array}{ll}\text { MDA-MB-231 } & \text { IC } 50=1.395 \mu \mathrm{M} \\ \text { MCF-10A } & \text { IC50 }=40.87 \mathrm{nM} \\ \text { MCF-7 } & \text { IC50 }=543 \mathrm{nM} \\ \text { BT549 } & \text { IC } 50=1.08 \mathrm{nM}\end{array}$

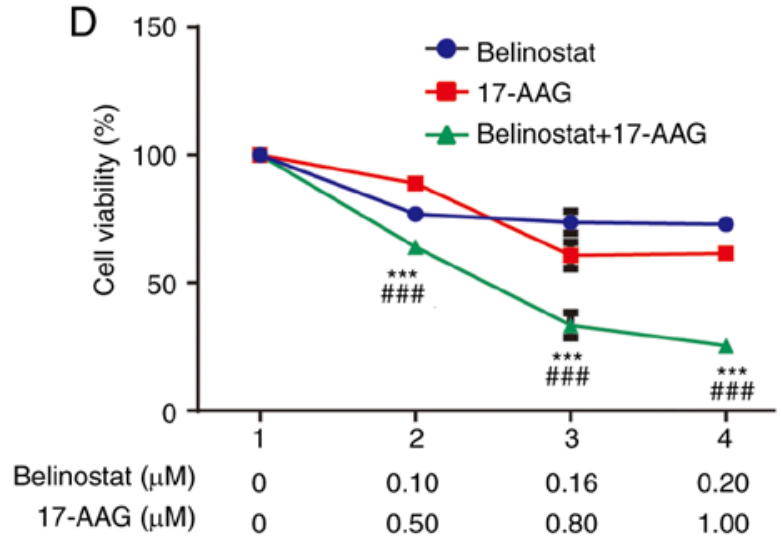

Figure 2. Synergistic effect exists between 17-AAG and Belinostat in breast cancer cell lines. (A) $\mathrm{IC}_{50}$ value for Belinostat against the viability of breast cancer cell lines following compound treatment for $72 \mathrm{~h}$. (B) $\mathrm{IC}_{50}$ value for 17-AAG against the viability of breast cancer cell lines following compound treatment for $72 \mathrm{~h}$. (C) Synergistic effect between 17-AAG and Belinostat presented as the Fa-CI curve plotted by the CompuSyn software. Squares represent combined groups of different concentrations. $\mathrm{Cl}<1$ indicated that synergistic effect was observed for the combination of 17-AAG and Belinostat. (D) Significant enhancement of growth inhibition was observed for the three concentration groups following combined treatment with 17-AAG and Belinostat for $72 \mathrm{~h}$. Data are presented as the mean \pm SEM. ${ }^{* * * *} \mathrm{P}<0.001$ vs. Belinostat; ${ }^{\# \# /} \mathrm{P}<0.001$ vs. $17-\mathrm{AAG}$. CI, combination index; Fa, cell inhibition.

A

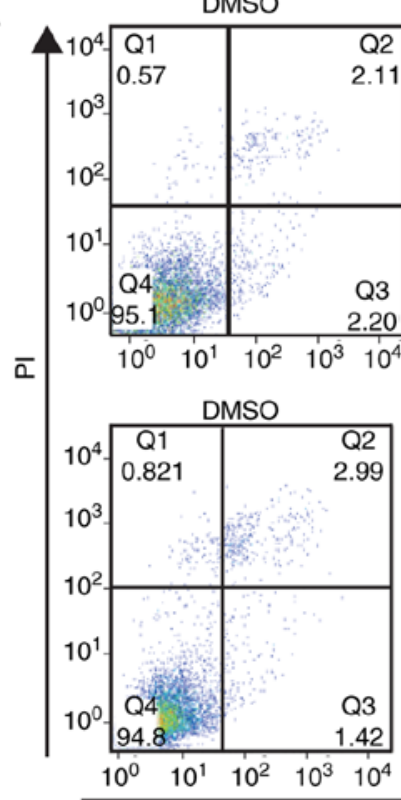

Belinostat $0.1 \mu \mathrm{M}$

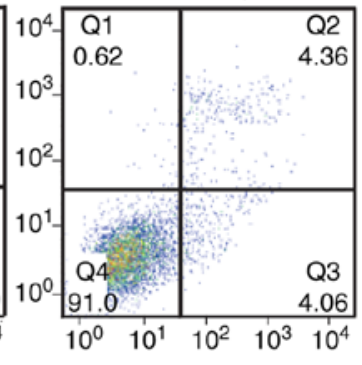

Q3 4.06

Belinostat $0.2 \mu \mathrm{M}$

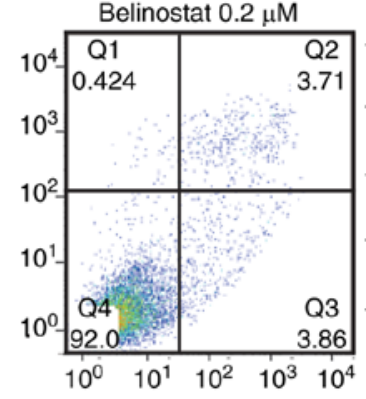

17-AAG $0.5 \mu \mathrm{M} \quad$ Belinostat $0.1 \mu \mathrm{M}$ \& 17-AAG $0.5 \mu \mathrm{M}$
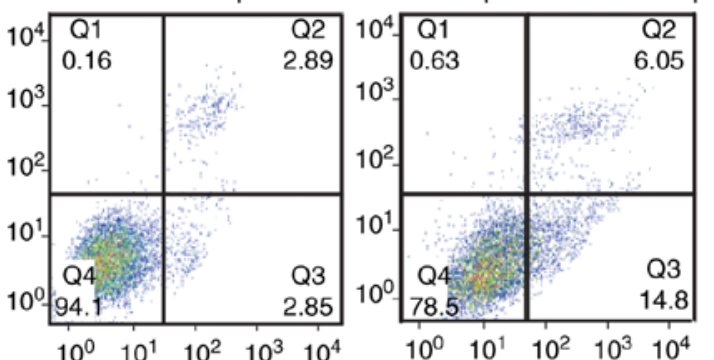

Belinostat $0.2 \mu \mathrm{M} \&$ 17-AAG $1.0 \mu \mathrm{M}$

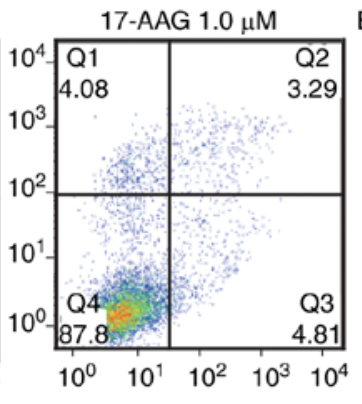

Q3

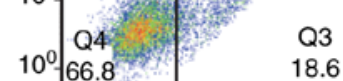

18.6

Figure 3. Combination of 17-AAG and Belinostat induces enhanced cell cycle arrest and apoptosis. (A) Increased apoptosis was observed in MDA-MB-231 cells, for the two combination groups of 17-AAG and Belinostat, compared with treatment with 17-AAG or Belinostat alone. 


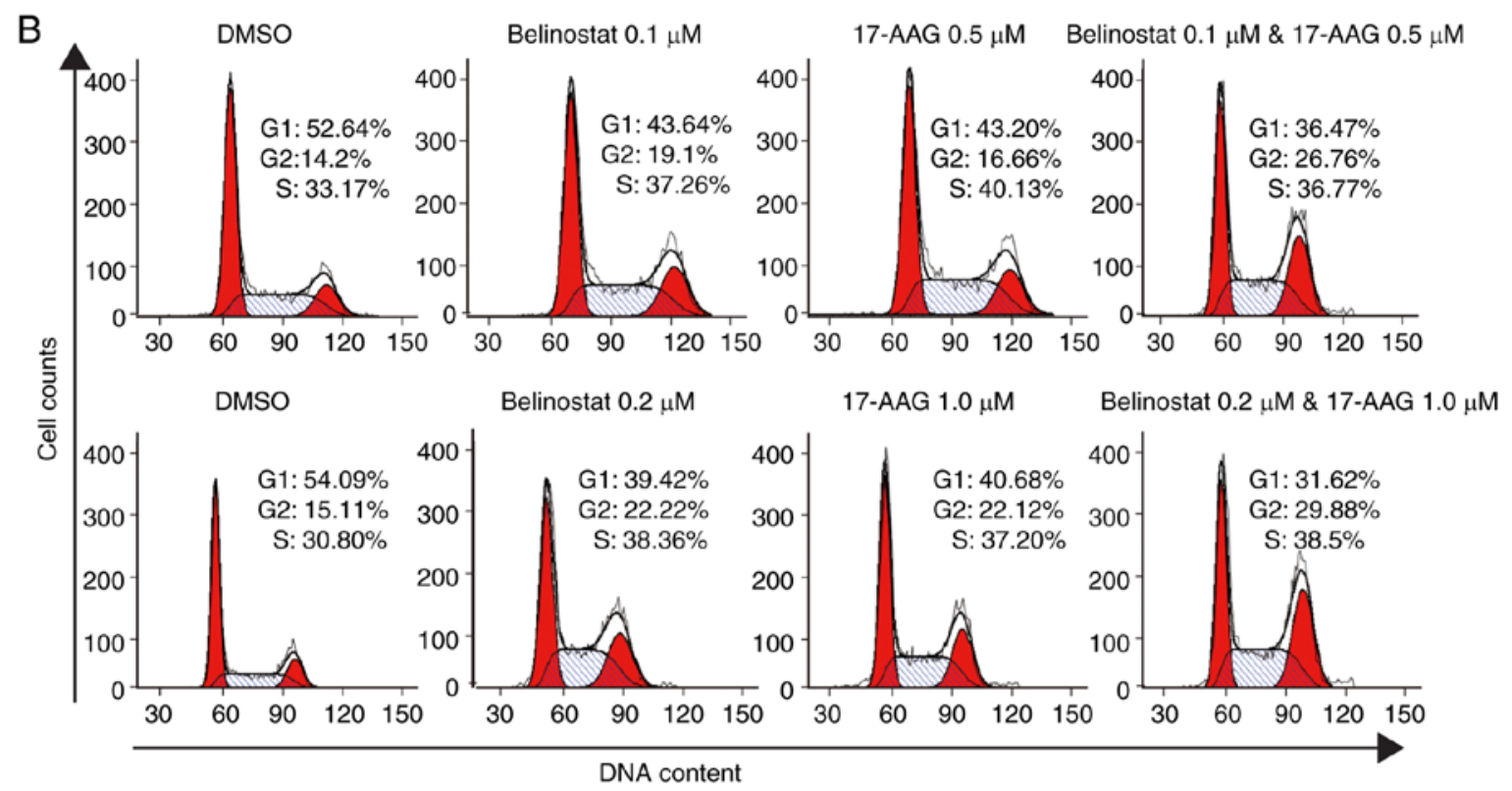

C

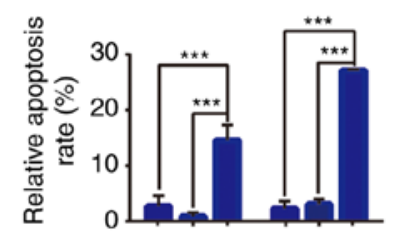

Belinostat $(\mu \mathrm{M}) \quad 0.1-0.10 .2-0.2$

17-AAG $(\mu \mathrm{M})-0.50 .5-11$

E
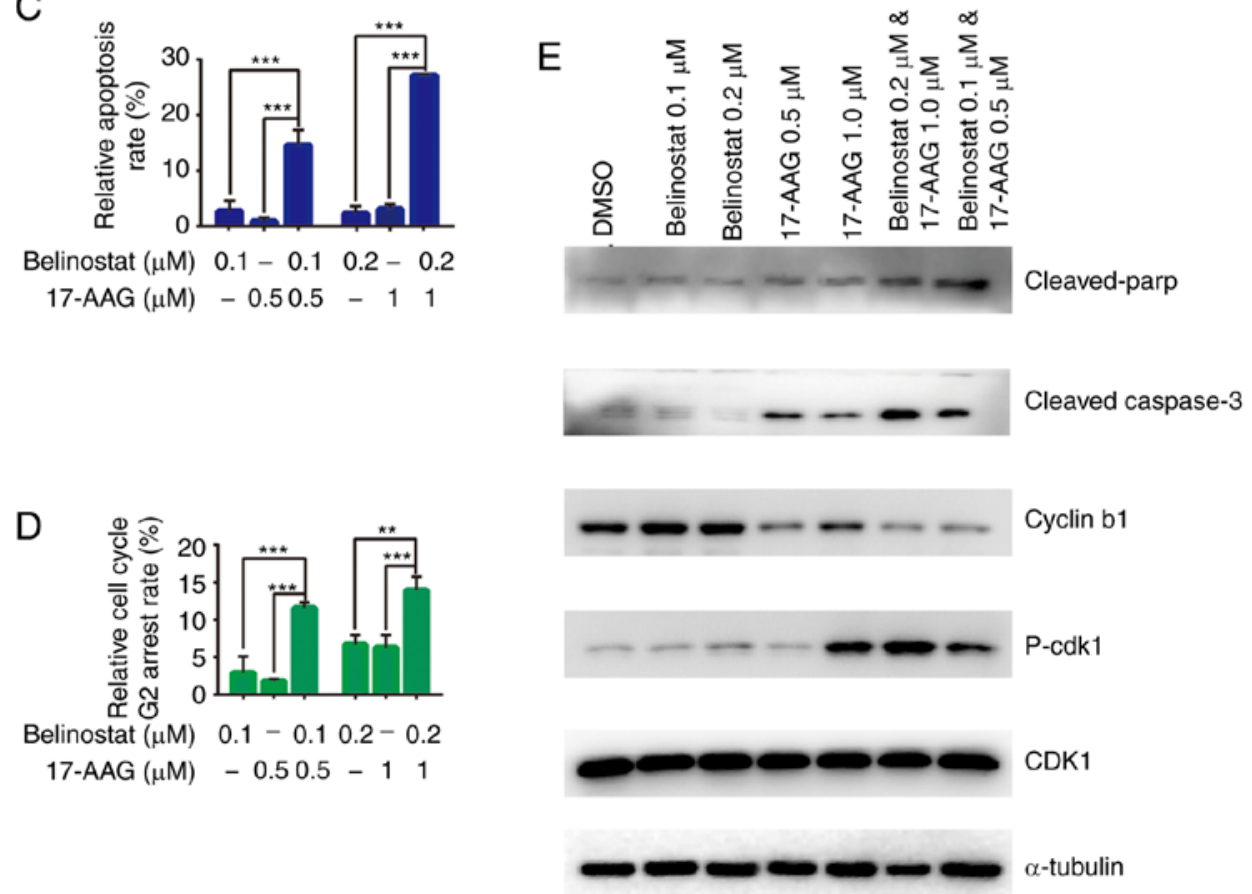

Figure 3. Continued. Combination of 17-AAG and Belinostat induces enhanced cell cycle arrest and apoptosis. (B) Increased $\mathrm{G}_{2} / \mathrm{M}$ cell cycle arrest was observed in MDA-MB-231 cells for the two combination groups of 17-AAG and Belinostat, compared with treatment with 17-AAG or Belinostat alone. (C) Quantified rate of apoptosis for each sample following compound treatment for $72 \mathrm{~h}$. (D) Quantified rate of $\mathrm{G}_{2} / \mathrm{M}$ cell cycle arrest for each sample, following compound treatment for $72 \mathrm{~h}$. (E) Western blotting results were consistent with the elevated apoptosis and cell cycle arrest revealed by flow cytometry. Data are presented as the mean $\pm \mathrm{SEM} .{ }^{* *} \mathrm{P}<0.01,{ }^{* * *} \mathrm{P}<0.001$. p-, phosphorylated-.

reciprocal interactions may exist between HSP90 and HDAC6. To determine whether Belinostat affected HSP90 expression, and whether 17-AAG affected the protein abundance of HDAC6, qPCR and western blotting were performed. Subsequently, it was demonstrated that Belinostat downregulated the transcription levels of HSP90 (HSP90AA1 and HSP90AB1; Fig. 4A). However, Belinostat did not reduce the HSP90 protein level (Fig. 4B). Compared with the treatment with Belinostat alone, the acetylation of HSP90 was sharply enhanced in the combination group, indicating that 17-AAG amplified the acetylation effect of Belinostat on HSP90. Although Belinostat induced higher acetylation of $\alpha$-tubulin than 17-AAG, this effect was not further enhanced in the combination group. Similarly, the protein abundance of HDAC6 was decreased following treatment with 17-AAG alone, whereas this effect was not further enhanced in the combination group (Fig. 4B).

RNA-seq analysis suggests that the combination of 17-AAG and Belinostat may achieve enhanced inhibition of the migration and invasion of MDA-MB-231 cells. To determine the specific genes and pathways that are responsible for the synergistic effect of the combination of 17-AAG and Belinostat, 


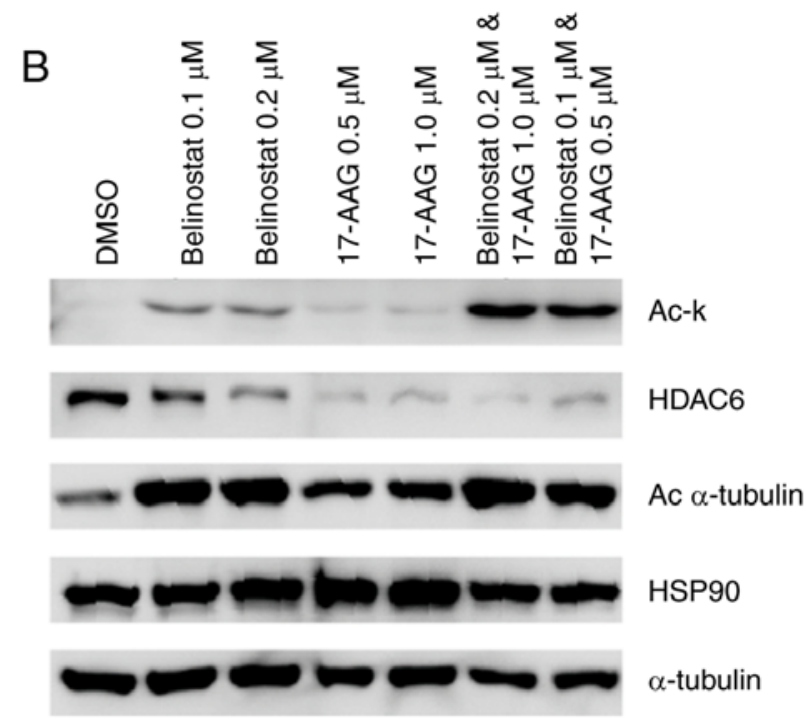

Figure 4. Reciprocal interactions between HSP90i 17-AAG and HDAC6i Belinostat. (A) HDAC6i Belinostat decreased the mRNA expression levels of HSP90 subunits (HSP90AA1 and HSP90AB1) in a concentration-dependent manner. MDA-MB-231 cells were treated with $0.1 \mu \mathrm{M}$ or $0.2 \mu \mathrm{M}$ Belinostat for $72 \mathrm{~h}$. (B) HSP90i 17-AAG significantly enhanced the acetylation effect of Belinostat on HSP90, as shown for Ac-k, whereas 17-AAG alone showed stronger inhibition of HDAC6 expression than Belinostat alone. 17-AAG alone increased the acetylation level of $\alpha$-tubulin, while this effect was enhanced in the combination group. HSP90 and $\alpha$-tubulin were used as internal references, and compound treatment duration was $72 \mathrm{~h}$. Data are shown as the mean \pm SEM. ${ }^{* * *} \mathrm{P}<0.001$. HSP90i, HSP90 inhibitor; HDAC6i, HDAC6 inhibitor; HDAC6, histone deacetylase 6; HSP90, heat shock protein 90; Ac, acetylated; Ac-k, Acetylated-lysine antibody.

A
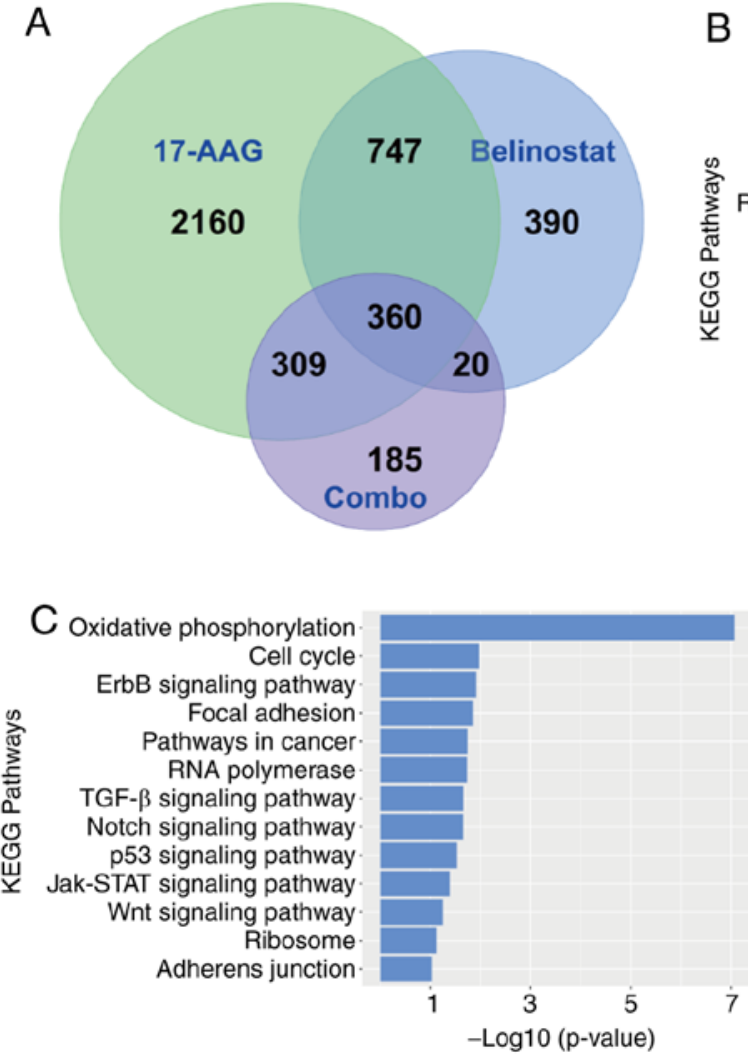
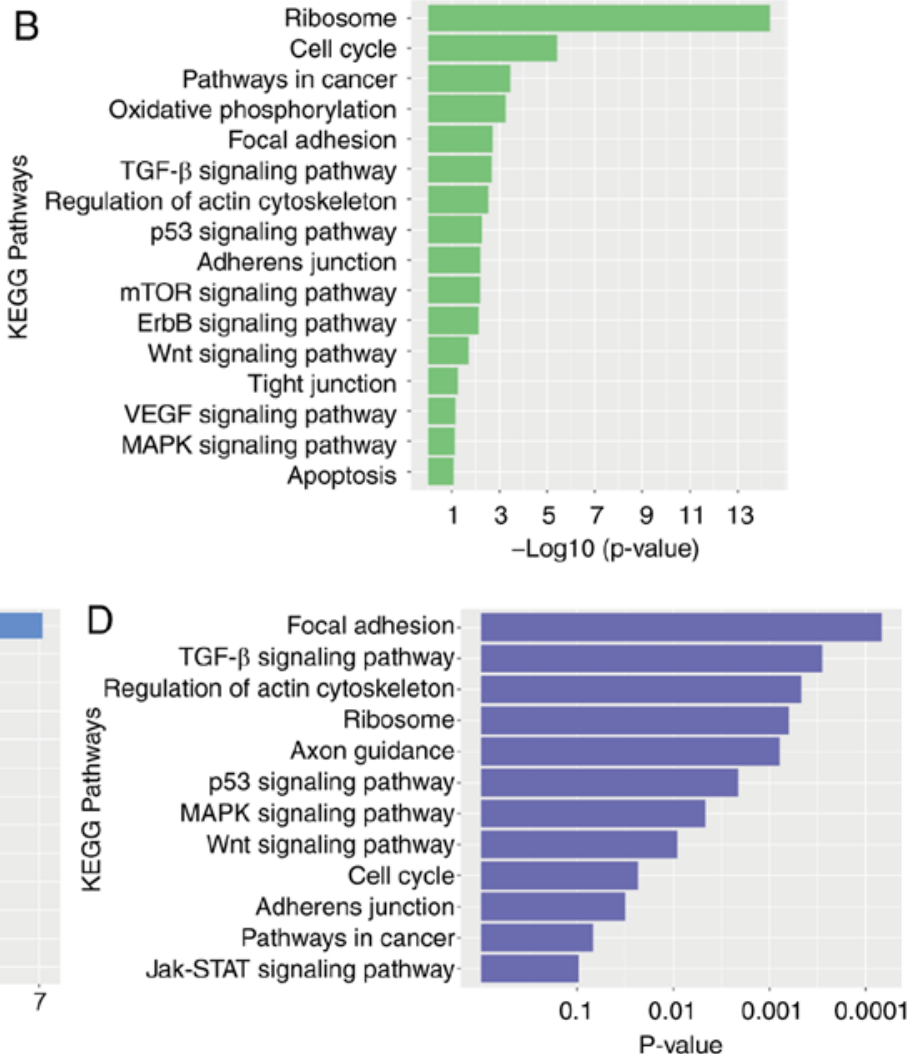

Figure 5. Pathway statistics and heatmap analysis for RNA-sequencing data of different treatment groups. (A) Venn diagram for shared and unique numbers of differentially expressed genes in the treatment groups of 17-AAG alone, Belinostat alone, and the combination of 17-AAG and Belinostat. The total number of shared differentially expressed genes for the three treatment groups was 360 , whereas the total number of unique differentially expressed genes for the combination group was 185. (B) Most enriched KEGG pathways of MDA-MB-231 cells, following the treatment with 17-AAG alone. The 'Cell cycle' and 'Oxidative phosphorylation' pathways were more significantly enriched than three migration-related pathways, including 'Focal adhesion', 'TGF-beta signaling pathway' and 'Regulation of actin cytoskeleton'. (C) Most enriched KEGG pathways of MDA-MB-231 cells following treatment with Belinostat alone. The 'Cell cycle' and 'Oxidative phosphorylation' pathways were more significantly enriched than three migration-related pathways, including 'Focal adhesion' and 'TGF-beta signaling pathway'. (D) Most enriched KEGG pathways of MDA-MB-231 cells following combined treatment with 17-AAG and Belinostat. Unlike for the treatment groups of 17-AAG or Belinostat alone, the 'Focal adhesion', 'TGF-beta signaling pathway' and 'Regulation of actin cytoskeleton' were more enriched than the 'Cell cycle' pathway, and other typical signaling pathways, including P53 signaling pathway, MAPK signaling pathway and Wnt signaling pathway. 
E

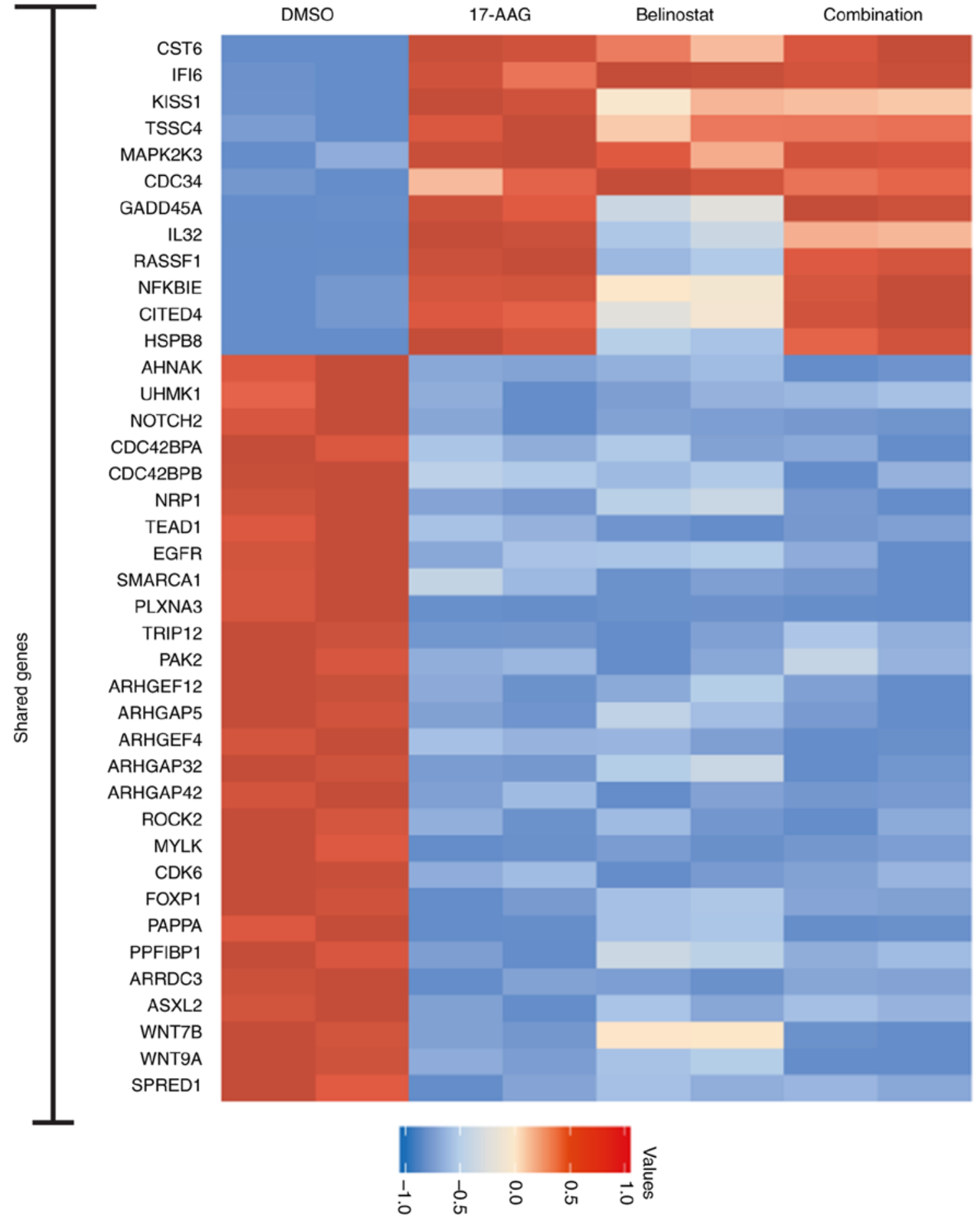

Figure 5. Continued. Pathway statistics and heatmap analysis for RNA-sequencing data of different treatment groups. ((E) Heatmap of selected differentially expressed genes from the shared list $(\mathrm{n}=360)$ of the three treatment groups, including 17-AAG alone, Belinostat alone and the combination group. These genes are associated with the migration or cytoskeleton remodeling of cells, according to previous studies (82-84). The relative expression values were compared with the DMSO group, and relatively higher expression is presented in red, whereas relatively lower expression is presented in blue.

RNA-seq was carried out using MDA-MB-231 cells treated with 17-AAG alone, Belinostat alone, and the combination of 17-AAG and Belinostat. The $\mathrm{IC}_{50}$ ratio of Belinostat and 17-AAG was $\sim 1$ vs. 5, as shown in Fig. $2 \mathrm{~A}$ and B, and the concentration used for RNA-seq was selected according to the previously calculated CI value, apoptosis and cell cycle experiments. When the dose for 17-AAG was $1.0 \mu \mathrm{M}$ and that for Belinostat was $0.2 \mu \mathrm{M}$, cell viability and apoptosis data exhibited an improved combination effect. Overall, this dosage was selected for RNA-Seq exploration. The results demonstrated that the numbers of differentially expressed genes were 3,576, 1,517 and 874, for the treatment of 17-AAG alone compared with the DMSO group, Belinostat alone compared with the DMSO group, and the combination group compared with the DMSO group, respectively. The numbers of shared and unique differentially expressed genes 


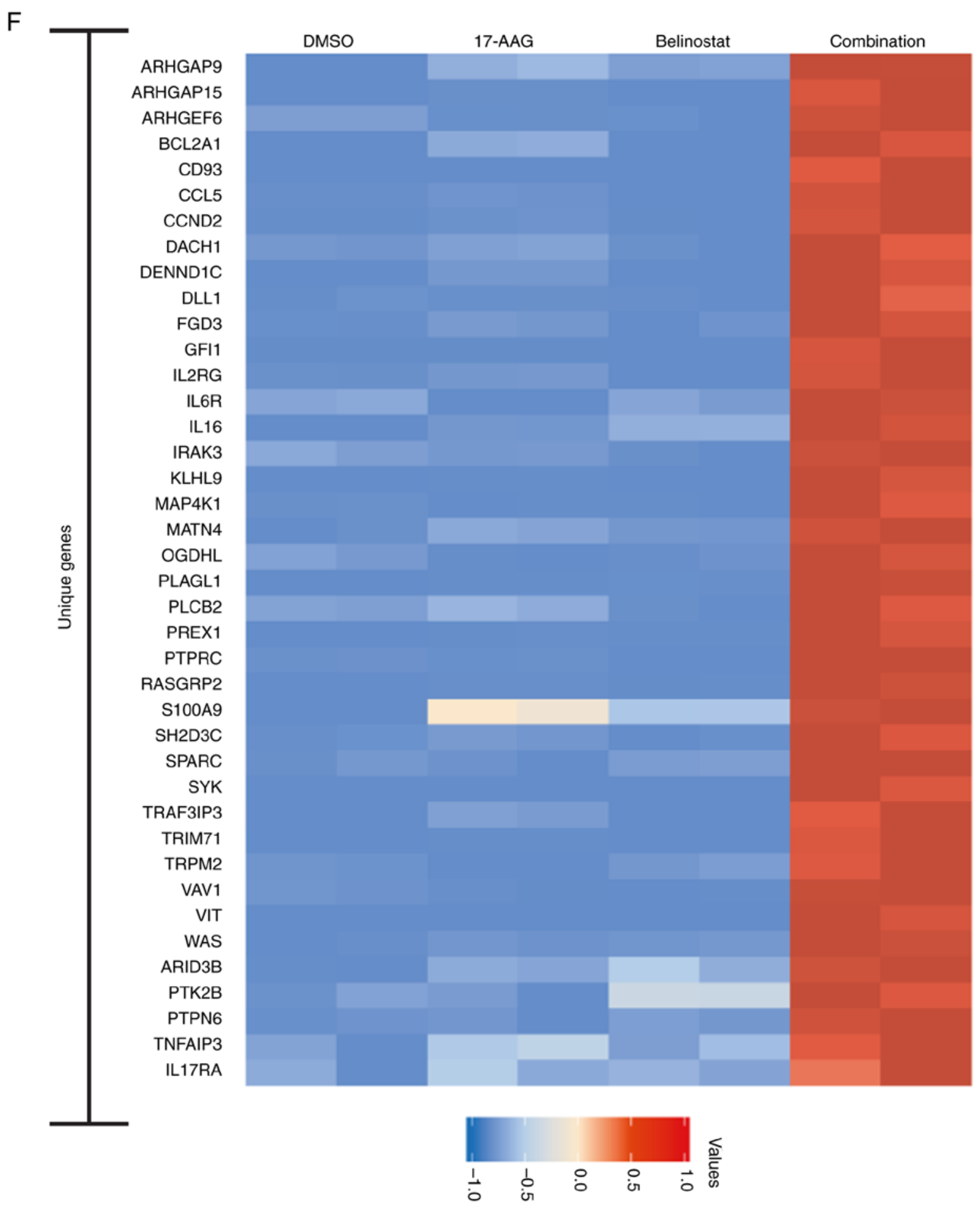

Figure 5. Continued. Pathway statistics and heatmap analysis for RNA-sequencing data of different treatment groups. (F) Heatmap of selected differentially expressed genes from the unique list $(\mathrm{n}=185)$ for the combination group, instead of the treatment groups of 17-AAG or Belinostat alone. These genes were associated with the migration or survival of tumor cells, according to previous studies (85-87). The relative expression values were compared with the DMSO group, and relatively higher expression was presented in red, whereas relatively lower expression was presented in blue. KEGG, Kyoto Encyclopedia of Genes and Genomes.

for each treatment group were presented as a Venn diagram (Fig. 5A). In terms of pathways analysis, the P-values for each significantly enriched KEGG pathway were plotted as a histogram for each treatment group, and the length of each bar is proportional to the P-value of each KEGG pathway. the 'cell cycle' pathway was more significantly enriched than the 'TGF-beta signaling pathway' and the 'Focal adhesion' pathway, for both the treatment of 17-AAG alone, or Belinostat alone (Fig. 5B and C). However, 'Focal adhesion', 'TGF-beta signaling pathway' and 'Regulation of actin cytoskeleton' were the most significantly enriched KEGG pathways in the combination group (Fig. 5D). For treatment with 17-AAG alone, the P-values for 'Focal adhesion', 'TGF-beta signaling pathway' and 'Regulation of actin cytoskeleton' were $1.9 \times 10^{-3}, 2.1 \times 10^{-3}$ 
A

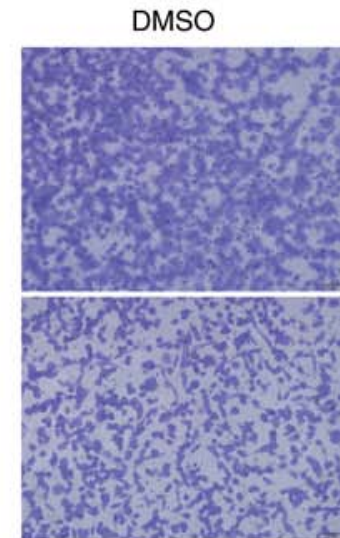

17-AAG $1 \mu \mathrm{M}$
Belinostat $0.2 \mu \mathrm{M}$

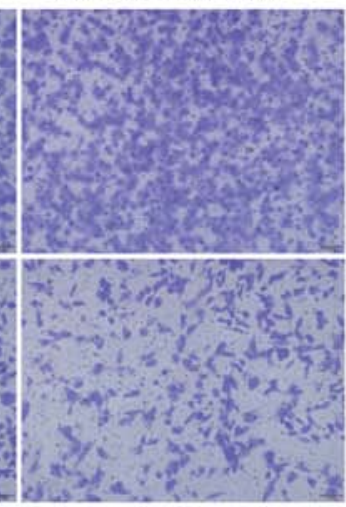

17-AAG $1 \mu \mathrm{M} \&$

Belinostat $0.2 \mu \mathrm{M}$

DMSO

Belinostat $0.2 \mu \mathrm{M}$

17-AAG $1 \mu \mathrm{M}$

17-AAG $1 \mu \mathrm{M}$ \& Belinostat $0.2 \mu \mathrm{M}$

Cell invasion

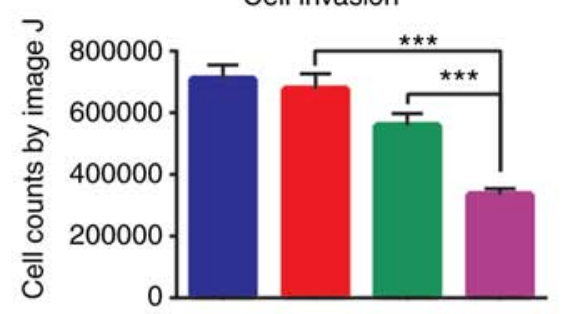

B
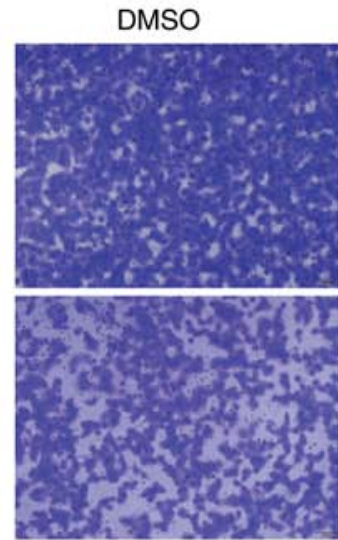

17-AAG $1 \mu \mathrm{M}$

Belinostat $0.2 \mu \mathrm{M}$
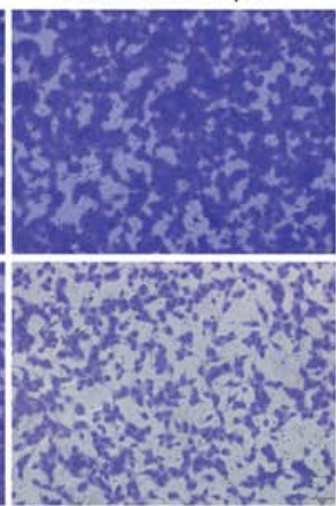

17-AAG $1 \mu \mathrm{M}$ \&

Belinostat $0.2 \mu \mathrm{M}$

DMSO

Belinostat $0.2 \mu \mathrm{M}$

17-AAG $1 \mu \mathrm{M}$

17-AAG $1 \mu \mathrm{M}$ \& Belinostat $0.2 \mu \mathrm{M}$

Cell migration

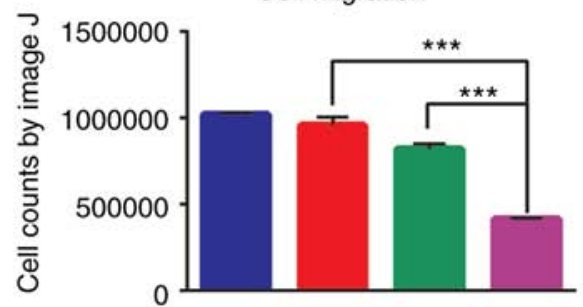

0

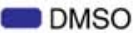

Belinostat $0.2 \mu \mathrm{M}$

17-AAG $1 \mu \mathrm{M}$

17-AAG $1 \mu \mathrm{M}$ \& Belinostat $0.2 \mu \mathrm{M}$

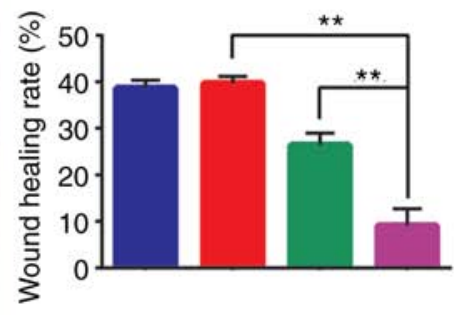

Figure 6. Enhanced inhibition of the migration and invasion of MDA-MB-231 cells. (A) Transwell migration assays demonstrated that enhanced inhibition was observed for the combination group of 17-AAG and Belinostat in MDA-MB-231 cells. Magnification, $\mathrm{x} 40$. (B) Transwell invasion assay demonstrated that enhanced inhibition was observed for the combination group of 17-AAG and Belinostat in MDA-MB-231 cells. Magnification, $\mathrm{x} 40$. (C) Wound healing assays revealed that enhanced inhibition was observed for the combination group of 17-AAG and Belinostat in MDA-MB-231 cells. Magnification, x40.

and $2.9 \times 10^{-3}$, respectively. For treatment with Belinostat alone, the P-values for 'Focal adhesion' and 'TGF-beta signaling pathway' were 0.014 and 0.022 , respectively. However, in the combination group, the P-values for 'Focal Adhesion', 'TGF-beta signaling pathway' and 'Regulation of actin cytoskeleton' were $6.8 \times 10^{-5}, 2.9 \times 10^{-4}$ and $4.7 \times 10^{-4}$, respectively. In addition, considering the over-representation of the 'Oxidative phosphorylation' pathway in MDA-MB-231 cells following with treatment with Belinostat alone, the accumulation ROS in different groups was examined. It was identified that the ROS level was significantly higher in the combination group (Fig. S1A). In addition, several genes that regulate relevant signaling pathways were also significantly affected in the combination group, including EGFR, COX5B and UBA52 (Fig. S1B). Consistent with the pathway analysis, dozens of migration-associated genes were identified in the list of differentially expressed genes. Some of them were observed in the shared list of all the treatment groups, including the treatment with 17-AAG alone, Belinostat alone and the combination group (Fig. 5E), whereas some of them were observed only in the list of the combination group (Fig. 5F). As these pathways and genes mainly mediate the migration and invasion of cancer cells, these findings indicated that the combination of 17-AAG and Belinostat may have enhanced the inhibition of the migration and invasion of MDA-MB-231 cells compared with treatment with 17-AAG or Belinostat alone. 


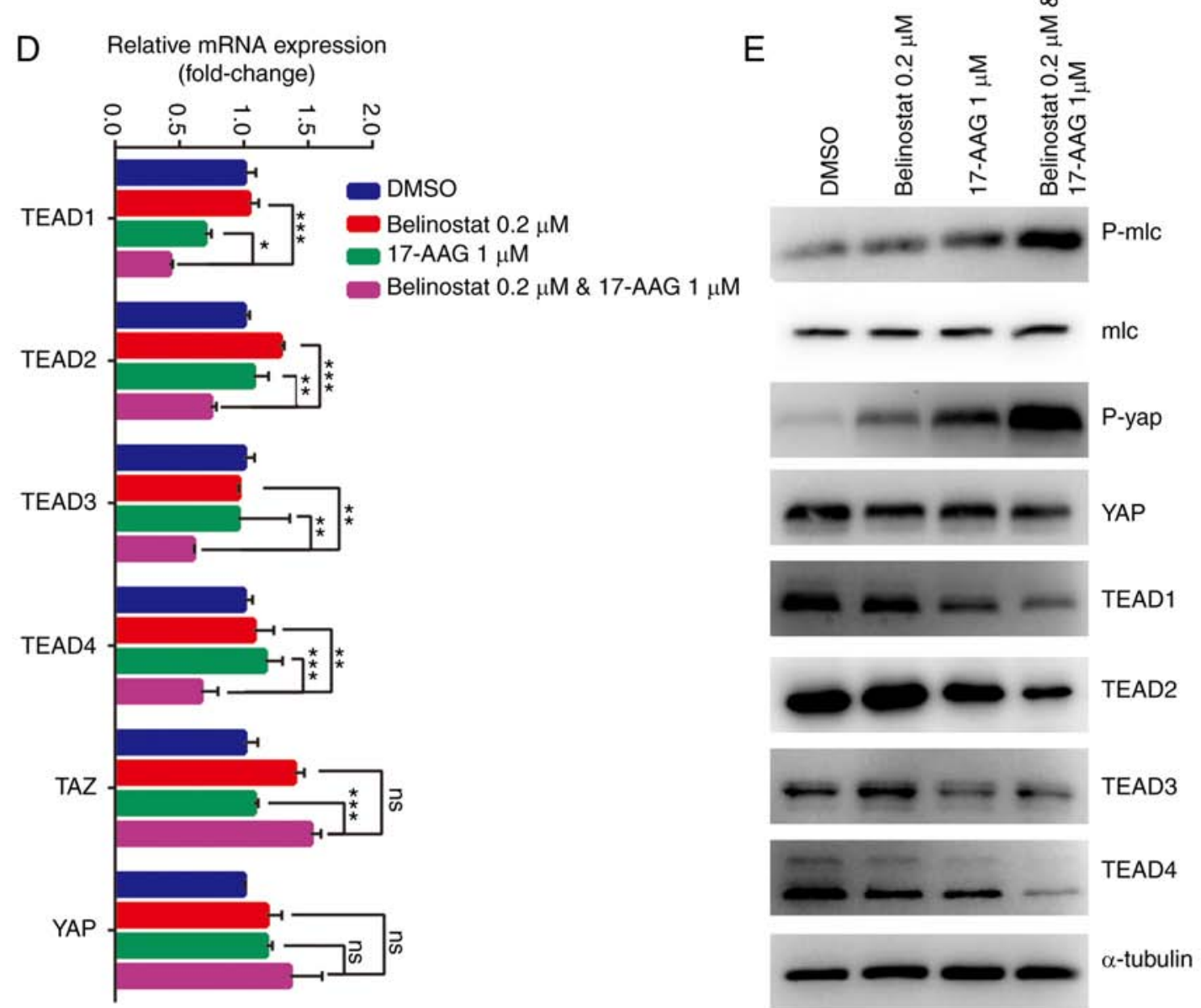

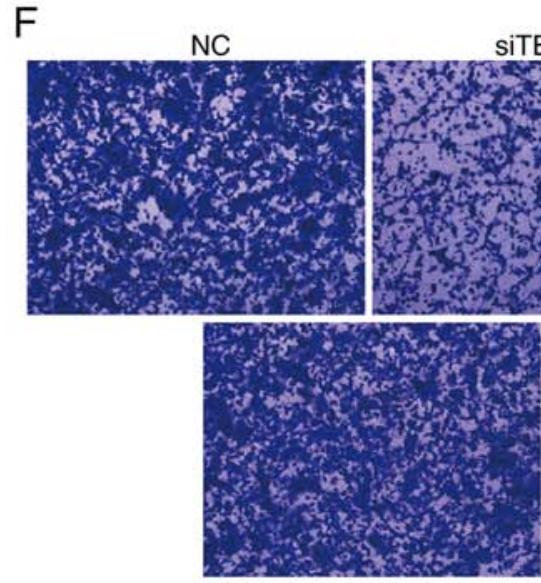

SiTEAD3

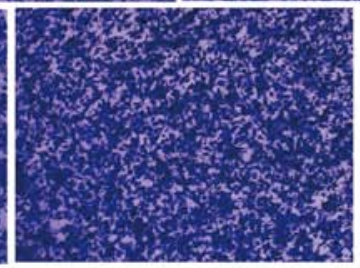

siTEAD4
SITEAD2
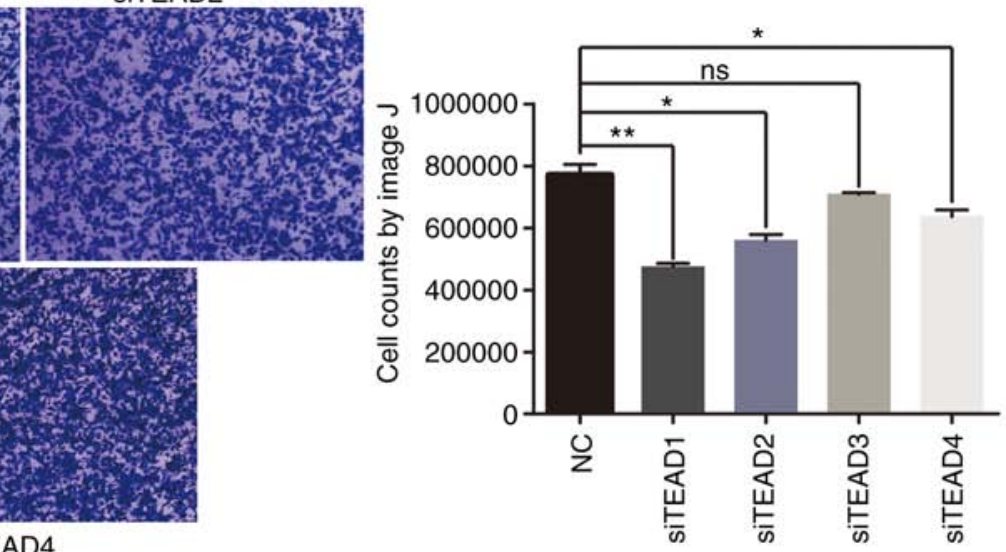

Figure 6. Continued. Enhanced inhibition of the migration and invasion of MDA-MB-231 cells. (D) Significant downregulation of expression was observed for the TEAD family proteins in the combination group compared with in the treatment groups of 17-AAG or Belinostat alone. (E) Phosphorylation of YAP and MLC was significantly increased in the combination group, indicating the suppression of migration and invasion-associated pathways. Decreased protein abundance of the TEAD family was consistent with the mRNA downregulation. (F) Transwell migration assays demonstrated that the knockdown of TEADs genes inhibited the migration of MDA-MB-231 cells. Magnification, $x 40$. Data are presented as the mean \pm SEM. ${ }^{*} \mathrm{P}<0.05,{ }^{* *} \mathrm{P}<0.01,{ }^{* * * *} \mathrm{P}<0.001$. $\mathrm{p}-$, phosphorylated; TEAD, TEA domain family member; ns, not significant; YAP, YY1 associated protein 1; TAZ, tafazzin; MLC, modulator of VRAC current 1; si, small interfering RNA; NC, negative control.

Combination of 17-AAG and Belinostat leads to enhanced inhibition of the migration and invasion of MDA-MB-231 cells. To confirm whether the combination of 17-AAG and Belinostat may have inhibitory effects on migration and invasion, MDA-MB-231 cells were treated with single or combined compounds and subjected to Transwell and wound-healing assays. The doses for 17-AAG and for Belinostat were consistent with those for
RNA-seq. Compared with the treatment of 17-AAG alone, or Belinostat alone, the numbers of migrating and invasive cells were decreased following the combined treatment with 17-AAG and Belinostat for $24 \mathrm{~h}$ (Fig. 6A and B). Similarly, in the wounding healing assay, it was identified that the migration of cells was significantly suppressed following the combined treatment with 17-AAG and Belinostat for $24 \mathrm{~h}$ (Fig. 6C). According to the 


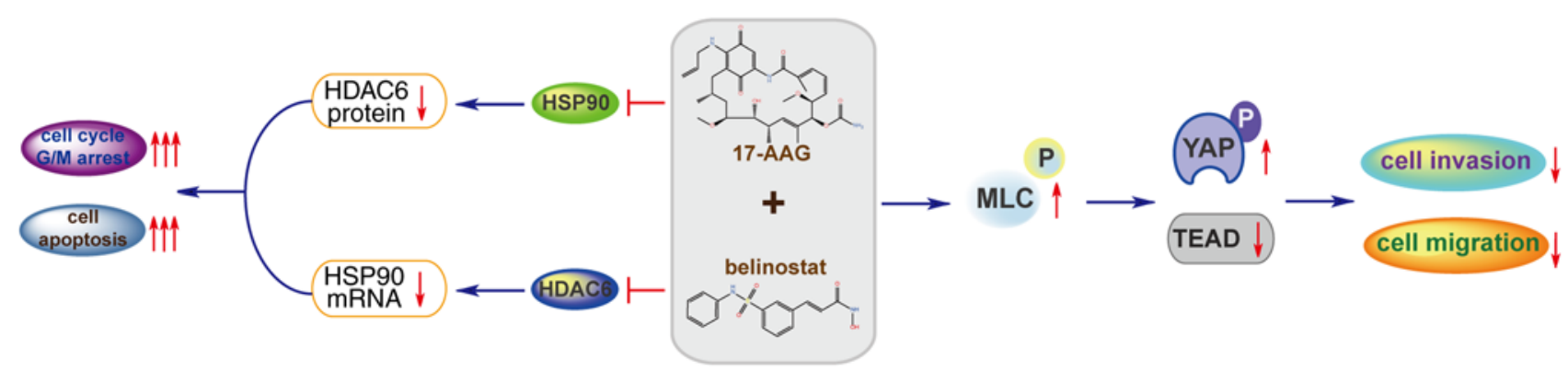

Figure 7. Proposed mechanism for the combination of 17-AAG and Belinostat exhibiting inhibitory effects on proliferation and invasion. HDAC6, histone deacetylase 6; HSP90, heat shock protein 90; TEAD, TEA domain family member; MLC, modulator of VRAC current 1; YAP, YY1 associated protein 1.

RNA-seq data analysis, relevant signaling pathways and genes mediating cell migration and invasion were investigated $(60,61)$. TEAD1 is one of the differentially expressed genes shared by the single and combined treatment groups (Fig. 5E). Additionally, significant downregulation was observed for the TEAD family proteins in the combination group (Fig. 6D). Consistent with RNA sequencing results (Fig. 5E), western blotting results demonstrated that the abundance of TEAD family proteins was decreased in the combination group (Fig. 6E). Additionally, the phosphorylation of YAP and MLC was increased in the combination group. Subsequently, siRNA was used to knockdown TEAD genes in MDA-MB-231 cells. The knockdown efficiency of each siRNA was $>80 \%$ compared with the normal group (Fig. S2A). Additionally, the protein expression levels of TEADs were decreased (Fig. S2B). As shown in the results of the cell migration assay (Fig. 6F), TEAD1 exhibited a greater effect on migration of MDA-MB-231 cells than other TEADs, whereas TEAD3 had no effect on cell migration.

\section{Discussion}

The present study reported the synergistic effect of the HSP90 inhibitor 17-AAG and the HDAC6 inhibitor Belinostat on the proliferation, as well as migration and invasion, of TNBC MDA-MB-231 cells. HSP90 has been reported as a biomarker of TNBC $(24,25)$, and HDACs are considered to be a therapeutic target of TNBC (62). According to previous studies, HSP90 regulates the protein folding of HDAC6, whereas HDAC6 reversely promotes the acetylation of HSP90 $(38,39)$. Higher expression levels of HSP90 and HDAC6 were observed in TNBC BT549 and MDA-MB-231 cell lines compared with in the non-TNBC MCF-7 cell line and normal breast MCF-10A cell line, suggesting that the combined treatment of HSP90 inhibitor and HDAC6 inhibitor may achieve synergistic efficacy (63). Subsequently, it was revealed that the combined treatment with HSP90 inhibitor 17-AAG and HDAC6 inhibitor Belinostat synergistically inhibited the proliferation of MDA-MB-231 cells, with a $\mathrm{CI}<1$ in three different concentration groups (Fig. 1D). Additionally, the inhibition rate in the combination group was greater than the sum of inhibition rates of the two single-treatment groups, which is a remarkable feature of this combination formula.

According to previous studies of the interactions between HSP90 and HDAC6, the inhibitors of these two targets may crosstalk $(38,64,65)$. The results revealed that the HDAC6 inhibitor Belinostat downregulated the mRNA expression of
HSP90, whereas the HSP90 inhibitor 17-AAG significantly downregulated the protein abundance of HDAC6. Indeed, HDAC inhibitors have been identified to turn on gene expression via an increase in histone acetylation and chromatin opening (66). However, subsequent studies have revealed that open chromatin resulting from inhibition of histone deacetylases can result in either the upregulation or the repression of genes $(67,68)$. Due to this reciprocal interaction, the acetylation rate of HSP90 and $\alpha$-tubulin were significantly elevated in the combination group of 17-AAG and Belinostat. The difference between mRNA and protein expression may be caused by time delay between transcription and translation. The decrease in mRNA may require more time to impact the protein level. In order to investigate the involved genes and pathways which are responsible for the synergistic effect of the combination of 17-AAG and Belinostat, RNA-seq data was collected and analyzed. It was identified that migration and invasion-associated pathways were the most significantly enriched in the combination group. Subsequent results confirmed the significant downregulation of TEAD family proteins, and increased phosphorylation of YAP and MLC, indicating the suppression of the Hippo signaling pathway and Rho-mediated cell migration (Fig. 7). The present study revealed that the protein expression levels of YAP were decreased in the combination group, and previous studies have demonstrated that YAP is associated with the occurrence of breast cancer (69-71). YAP can enhance cell growth and tumor growth $(72,73)$. Therefore, the downregulation of YAP may explain why the combination group can inhibit cell proliferation better than a single drug. Overall, the combination of 17-AAG and Belinostat increased the phosphorylation of YAP and modulator of VRAC current 1 (MLC), and decreased the expression of YAP and TEAD family proteins, leading to the suppression of Hippo signaling pathway (74) and Rho-mediated cell migration $(75,76)$. These alterations may contribute to the enhanced inhibition of the combination group, in terms of migration and invasion of MDA-MB-231 cells. TEAD is a well investigated regulator that mediates the migration and invasion of cancer cells. Previous studies have indicated the key regulatory role of the YY1 associated protein 1(YAP)/TAZ/TEAD complex in the metastasis of breast cancer $(77,78)$. Transcriptional co-activator with PDZ-binding motif (TAZ) is structurally similar transcriptional co-factors involved in multiple cellular processes including proliferation, organ growth and stem cell differentiation with YAP (79). In addition, as a transcription factor, the alteration in TEAD expression may have a wider 
and deeper impact on the migration and invasion of cancer cells compared with various other genes. Previous studies have indicated the effect of HSP90 and HDAC6 $(80,81)$ in regulating the function of the YAP/TAZ/TEAD complex. However, the detailed mechanism of how the TEAD genes affected MDA-MB-231 cell migration requires further research. The observation in MDA-MB-231 cells require verification in BT549 or other TNBC cell lines in addition to in vivo studies to verify this effect. Overall, according to previous experiment on MDA-MB-231 cells, the combination of 17-AAG and Belinostat has great potential for the treatment of TNBC. However, the enhanced efficacy of this combination requires clinical data to substantiate, before it actually benefits the patients with TNBC.

In conclusion, as a heterogeneous subtype of breast cancer, TNBC is challenging for clinical treatment due to the high risk of metastasis and recurrence. The current study reported the enhanced inhibitory effect of the combination of 17-AAG and Belinostat on the proliferation, cell cycle progression and survival of TNBC MDA-MB-231 cells. Additionally, the inhibition rate in the combination group was greater than the sum of the inhibition rates in the single-treatment groups. According to the RNA-seq data analysis, this combination may exhibit enhanced inhibitory effects on the migration and invasion of MDA-MB-231 cells, which was subsequently confirmed by migration and invasion assays. In addition, it was revealed that this enhanced efficacy may be achieved through the suppression of the Hippo signaling pathway and Rho-mediated cell migration (78). Since the anti-metastasis feature of this combination has great potential for the treatment of TNBC, it was concluded that the effect and mechanism of this combination provided a novel strategy, as well as beneficial reference, for the clinical treatment of TNBC, based on experiments in MDA-MB-231 cells.

\section{Acknowledgements}

Not applicable.

\section{Funding}

The present study was financially supported by the CAS Strategic Priority Research Program (grant no. XDA12020353 to CL), the Institutes for Drug Discovery and Development, Chinese Academy of Sciences (grant no. CASIMM0120184015 to $\mathrm{CL}$ ), and the Shanghai Young Science and Technology Talents Sailing Plan (grant no. 19YF1457200 to HZ).

\section{Availability of data and materials}

The datasets used and/or analyzed during the current study are available from the corresponding author on reasonable request.

\section{Authors' contributions}

$\mathrm{CL}, \mathrm{KC}, \mathrm{HJ}, \mathrm{HX}$ and $\mathrm{HZ}$ designed the study and discovered the combination. YZ, HX, FX and ZC conducted the experiments of cell viability, flow cytometry, western blotting and migration assays. $\mathrm{HZ}$ and $\mathrm{BZ}$ analyzed the
RNA-seq data, and uploaded the raw data to the GEO database. $\mathrm{KC}, \mathrm{HJ}$ and $\mathrm{CL}$ were responsible for the collection and assembly of data. $\mathrm{YZ}$ and $\mathrm{HX}$ prepared the figures and wrote the manuscript. $\mathrm{KC}, \mathrm{HJ}$ and $\mathrm{HZ}$ revised the manuscript. CL and HZ supervised the project. All authors read and approved the final version of this manuscript and agree to be accountable for all aspects of the research in ensuring that the accuracy or integrity of any part of the work are appropriately investigated and resolved.

\section{Ethics approval and consent to participate}

Not applicable.

\section{Patient consent for publication}

Not applicable.

\section{Competing interests}

The authors declare that they have no competing interests.

\section{References}

1. Ito $\mathrm{H}$ and Matsuo $\mathrm{K}$ : Molecular epidemiology, and possible real-world applications in breast cancer. Breast Cancer 23: 33-38, 2016.

2. Khan MA, Jain VK, Rizwanullah M, Ahmad J and Jain K: $\mathrm{PI} 3 \mathrm{~K} / \mathrm{AKT} / \mathrm{mTOR}$ pathway inhibitors in triple-negative breast cancer: A review on drug discovery and future challenges. Drug Discov Today 24: 2181-2191, 2019.

3. Ellsworth RE, Blackburn HL, Shriver CD, Soon-Shiong P and Ellsworth DL: Molecular heterogeneity in breast cancer: State of the science and implications for patient care. Semin Cell Dev Biol 64: 65-72, 2017.

4. Harbeck N, Penault-Llorca F, Cortes J, Gnant M, Houssami N, Poortmans P, Ruddy K, Tsang J and Cardoso F: Breast cancer. Nat Rev Dis Primers 5: 66, 2019.

5. El Etreby MF, Liang Y, Wrenn RW and Schoenlein PV: Additive effect of mifepristone and tamoxifen on apoptotic pathways in MCF-7 human breast cancer cells. Breast Cancer Res Treat 51: 149-168, 1998.

6. Arab A, Yazdian-Robati R and Behravan J: HER2-Positive breast cancer immunotherapy: A focus on vaccine development. Arch Immunol Ther Exp (Warsz) 68: 2, 2020.

7. Chacón RD and Costanzo MV: Triple-negative breast cancer. Breast Cancer Res 12 (Suppl 2): S3, 2010.

8. Chang-Qing Y, Jie L, Shi-Qi Z, Kun Z, Zi-Qian G, Ran X, Hui-Meng L, Ren-Bin Z, Gang Z, Da-Chuan Y and Chen-Yan Z: Recent treatment progress of triple negative breast cancer. Prog Biophys Mol Biol 151: 40-53, 2020.

9. Lee YT, Tan YJ and Oon CE: Molecular targeted therapy: Treating cancer with specificity. Eur J Pharmacol 834: 188-196, 2018.

10. Bianchini G, Balko JM, Mayer IA, Sanders ME and Gianni L: Triple-negative breast cancer: Challenges and opportunities of a heterogeneous disease. Nat Rev Clin Oncol 13: 674-690, 2016.

11. Wein L, Luen SJ, Savas P, Salgado R and Loi S: Checkpoint blockade in the treatment of breast cancer: Current status and future directions. Br J Cancer 119: 4-11, 2018.

12. Lee A and Djamgoz MBA: Triple negative breast cancer: Emerging therapeutic modalities and novel combination therapies. Cancer Treat Rev 62: 110-122, 2018.

13. Gahr S, Ocker M, Ganslmayer M, Zopf S, Okamoto K, Hartl A, Leitner S, Hahn EG and Herold C: The combination of the histone-deacetylase inhibitor trichostatin $\mathrm{A}$ and gemcitabine induces inhibition of proliferation and increased apoptosis in pancreatic carcinoma cells. Int J Oncol 31: 567-576, 2007.

14. Jang JH, Cho YC, Kim KH, Lee KS, Lee J, Kim DE, Park JS, Jang BC, Kim S, Kwon TK and Park JW: BAI, a novel Cdk inhibitor, enhances farnesyltransferase inhibitor LB42708-mediated apoptosis in renal carcinoma cells through the downregulation of Bcl-2 and c-FLIP (L). Int J Oncol 45: 1680-1690, 2014. 
15. Wang $\mathrm{XN}$, Wang $\mathrm{KY}$, Zhang $\mathrm{XS}$, Yang $\mathrm{C}$ and Li $\mathrm{XY}$ 4-Hydroxybenzoic acid (4-HBA) enhances the sensitivity of human breast cancer cells to adriamycin as a specific HDAC6 inhibitor by promoting HIPK2/p53 pathway. Biochem Biophys Res Commun 504: 812-819, 2018.

16. Schopf FH, Biebl MM and Buchner J: The HSP90 chaperone machinery. Nat Rev Mol Cell Boil 18: 345-360, 2017.

17. Talaei S, Mellatyar H, Asadi A, Akbarzadeh A, Sheervalilou R and Zarghami N: Spotlight on 17-AAG as an Hsp90 inhibitor for molecular targeted cancer treatment. Chem Biol Drug Des 93: 760-786, 2019.

18. Kamal A, Thao L, Sensintaffar J, Zhang L, Boehm MF, Fritz LC and Burrows FJ: A high-affinity conformation of Hsp90 confers tumour selectivity on Hsp90 inhibitors. Nature 425: 407-410, 2003.

19. Mellatyar H, Talaei S, Pilehvar-Soltanahmadi Y, Barzegar A, Akbarzadeh A, Shahabi A, Barekati-Mowahed $M$ and Zarghami N: Targeted cancer therapy through 17-DMAG as an Hsp90 inhibitor: Overview and current state of the art. Biomed Pharmacother 102: 608-617, 2018.

20. Zagouri F, Sergentanis TN, Chrysikos D, Papadimitriou CA, Dimopoulos MA and Psaltopoulou T: Hsp90 inhibitors in breast cancer: A systematic review. Breast 22: 569-578, 2013.

21. Pontes FSC, Pontes HAR, de Souza LL, de Jesus AS, Joaquim AMC, Miyahara LAN, Fonseca FP and Pinto Junior DS: Effect of 17-allylamino-17-demethoxygeldanamycin (17-AAG) on Akt protein expression is more effective in head and neck cancer cell lineages that retain PTEN protein expression. J Oral Pathol Med 47: 253-259, 2018.

22. Modi S, Stopeck A, Linden H, Solit D, Chandarlapaty S, Rosen N, D'Andrea G, Dickler M, Moynahan ME, Sugarman S, et al: HSP90 inhibition is effective in breast cancer: A phase II trial of tanespimycin (17-AAG) plus trastuzumab in patients with HER2-positive metastatic breast cancer progressing on trastuzumab. Clin Cancer Res 17: 5132-5139, 2011.

23. Raja SM, Clubb RJ, Bhattacharyya M, Dimri M, Cheng H, Pan W, Ortega-Cava C, Lakku-Reddi A, Naramura M, Band $\mathrm{V}$ and Band $\mathrm{H}$ : A combination of Trastuzumab and 17-AAG induces enhanced ubiquitinylation and lysosomal pathway-dependent ErbB2 degradation and cytotoxicity in ErbB2-overexpressing breast cancer cells. Cancer Boil Ther 7: 1630-1640, 2008.

24. Jensen MR, Schoepfer J, Radimerski T, Massey A, Guy CT, Brueggen J, Quadt C, Buckler A, Cozens R, Drysdale MJ, et al: NVP-AUY922: A small molecule HSP90 inhibitor with potent antitumor activity in preclinical breast cancer models. Breast Cancer Res 10: R33, 2008.

25. Cheng Q, Chang JT, Geradts J, Neckers LM, Haystead T, Spector NL and Lyerly HK: Amplification and high-level expression of heat shock protein 90 marks aggressive phenotypes of human epidermal growth factor receptor 2 negative breast cancer. Breast Cancer Res 14: R62, 2012.

26. Chelladurai P, Boucherat O, Stenmark K, Kracht M, Seeger W, Bauer UM, Bonnet S and Pullamsetti SS: Targeting histone acetylation in pulmonary hypertension and right ventricular hypertrophy. Br J Pharmacol: Nov 20, 2019 (Epub ahead of print).

27. Mirzaei H, Ghorbani S, Khanizadeh S, Namdari H, Faghihloo E and Akbari A: Histone deacetylases in virus-associated cancers. Rev Med Virol 30: e2085, 2020.

28. Guo P, Chen W, Li H, Li M and Li L: The histone acetylation modifications of breast cancer and their therapeutic implications. Pathol Oncol Res 24: 807-813, 2018.

29. Hassell KN: Histone deacetylases and their inhibitors in cancer epigenetics. Diseases 7: E57, 2019.

30. Huang M, Huang J, Zheng Y and Sun Q: Histone acetyltransferase inhibitors: An overview in synthesis, structure-activity relationship and molecular mechanism. Eur J Med Chem 178: 259-286, 2019.

31. Sanaei M and Kavoosi F: Histone deacetylases and histone deacetylase inhibitors: Molecular mechanisms of action in various cancers. Adv Biomed Res 8: 63, 2019.

32. Falkenberg KJ and Johnstone RW: Histone deacetylases and their inhibitors in cancer, neurological diseases and immune disorders. Nat Rev Drug Discov 13: 673-691, 2014.

33. Min A, Im SA, Kim DK, Song SH, Kim HJ, Lee KH, Kim TY, Han SW, Oh DY, Kim TY, et al: Histone deacetylase inhibitor, suberoylanilide hydroxamic acid (SAHA), enhances anti-tumor effects of the poly (ADP-ribose) polymerase (PARP) inhibitor olaparib in triple-negative breast cancer cells. Breast Cancer Res 17: 33, 2015 .
34. Bolden JE, Peart MJ and Johnstone RW: Anticancer activities of histone deacetylase inhibitors. Nat Rev Drug Discov 5: 769-784, 2006.

35. Tate CR, Rhodes LV, Segar HC, Driver JL, Pounder FN, Burow ME and Collins-Burow BM: Targeting triple-negative breast cancer cells with the histone deacetylase inhibitor panobinostat. Breast cancer Res 14: R79, 2012.

36. Aldana-Masangkay GI and Sakamoto KM: The role of HDAC6 in cancer. J Biomed Biotechnol 2011: 875824, 2011.

37. Boyault C, Sadoul K, Pabion M and Khochbin S: HDAC6, at the crossroads between cytoskeleton and cell signaling by acetylation and ubiquitination. Oncogene 26: 5468-5476, 2007.

38. Krämer $\mathrm{OH}$, Mahboobi S and Sellmer A: Drugging the HDAC6-HSP90 interplay in malignant cells. Trends Pharmacol Sci 35: 501-509, 2014.

39. Rao R, Fiskus W, Yang Y, Lee P, Joshi R, Fernandez P, Mandawat A, Atadja P, Bradner JE and Bhalla K: HDAC6 inhibition enhances 17-AAG-mediated abrogation of hsp90 chaperone function in human leukemia cells. Blood 112: 1886-1893, 2008.

40. Plumb JA, Finn PW, Williams RJ, Bandara MJ, Romero MR, Watkins CJ, La Thangue NB and Brown R: Pharmacodynamic response and inhibition of growth of human tumor xenografts by the novel histone deacetylase inhibitor PXD101. Mol Cancer Ther 2: 721-728, 2003

41. Qian X, LaRochelle WJ, Ara G, Wu F, Petersen KD, Thougaard A, Sehested M, Lichenstein HS and Jeffers M: Activity of PXD101, a histone deacetylase inhibitor, in preclinical ovarian cancer studies. Mol Cancer Ther 5: 2086-2095, 2006.

42. Paoluzzi L, Scotto L, Marchi E, Zain J, Seshan VE and Connor OA: Romidepsin and belinostat synergize the antineoplastic effect of bortezomib in mantle cell lymphoma. Clin Cancer Res 16: 554-565, 2010.

43. Thomas A, Rajan A, Szabo E, Tomita Y, Carter CA, Scepura B, Lopez-Chavez A, Lee MJ, Redon CE, Frosch A, et al: A phase I/II trial of belinostat in combination with cisplatin, doxorubicin, and cyclophosphamide in thymic epithelial tumors: A clinical and translational study. Clin Cancer Res 20: 5392-5402, 2014.

44. Kim SH, Kang JG, Kim CS, Ihm SH, Choi MG, Yoo HJ and Lee SJ: The heat shock protein 90 inhibitor SNX5422 has a synergistic activity with histone deacetylase inhibitors in induction of death of anaplastic thyroid carcinoma cells. Endocrine 51: 274-282, 2016.

45. Nguyen A, Su L, Campbell B, Poulin NM and Nielsen TO: Synergism of heat shock protein 90 and histone deacetylase inhibitors in synovial sarcoma. Sarcoma 2009: 794901, 2009.

46. Zismanov V, Drucker L and Gottfried M: ER homeostasis and motility of NSCLC cell lines can be therapeutically targeted with combined Hsp90 and HDAC inhibitors. Pulm Pharmacol Ther 26: 388-394, 2013.

47. Jamdade VS, Sethi N, Mundhe NA, Kumar P, Lahkar M and Sinha N: Therapeutic targets of triple-negative breast cancer: A review. Br J Pharmacol 172: 4228-4237, 2015.

48. Conlin AK and Seidman AD: Taxanes in breast cancer: An update. Curr Oncol Rep 9: 22-30, 2007.

49. Sikov WM, Berry DA, Perou CM, Singh B, Cirrincione CT, Tolaney SM, Kuzma CS, Pluard TJ, Somlo G, Port ER, et al: Impact of the addition of carboplatin and/or bevacizumab to neoadjuvant once-per-week paclitaxel followed by dose-dense doxorubicin and cyclophosphamide on pathologic complete response rates in stage II to III triple-negative breast cancer: CALGB 40603 (Alliance). J Clin Oncol 33: 13-21, 2015.

50. von Minckwitz G, Schneeweiss A, Loibl S, Salat C, Denkert C, Rezai M, Blohmer JU, Jackisch C, Paepke S, Gerber B, et al: Neoadjuvant carboplatin in patients with triple-negative and HER2-positive early breast cancer (GeparSixto; GBG 66): A randomised phase 2 trial. Lancet Oncol 15: 747-756, 2014.

51. Zhan Y, Chen Y, Liu R, Zhang H and Zhang Y: Potentiation of paclitaxel activity by curcumin in human breast cancer cell by modulating apoptosis and inhibiting EGFR signaling. Arch Pharm Res 37: 1086-1095, 2014.

52. Chou TC: Theoretical basis, experimental design, and computerized simulation of synergism and antagonism in drug combination studies. Pharmacol Rev 58: 621-681, 2006.

53. Ashton JC: Drug combination studies and their synergy quantification using the Chou-Talalay method--letter. Cancer Res 75: $2400,2015$.

54. Livak KJ and Schmittgen TD: Analysis of relative gene expression data using real-time quantitative PCR and the 2(-Delta Delta C(T)) method. Methods 25: 402-408, 2001. 
55. Kim D, Pertea G, Trapnell C, Pimentel H, Kelley R and Salzberg SL: TopHat2: Accurate alignment of transcriptomes in the presence of insertions, deletions and gene fusions. Genome Biol 14: R36, 2013.

56. Trapnell C, Roberts A, Goff L, Pertea G, Kim D, Kelley DR, Pimentel H, Salzberg SL, Rinn JL and Pachter L: Differential gene and transcript expression analysis of RNA-seq experiments with TopHat and cufflinks. Nat Protoc 7: 562-578, 2012.

57. Trapnell C, Hendrickson DG, Sauvageau M, Goff L, Rinn JL and Pachter L: Differential analysis of gene regulation at transcript resolution with RNA-seq. Nat Biotechnol 31: 46-53, 2013.

58. Feng G, Du P, Krett NL, Tessel M, Rosen S, Kibbe WA and Lin SM: A collection of bioconductor methods to visualize gene-list annotations. BMC Res Notes 3: 10, 2010.

59. Kovacs JJ, Murphy PJ, Gaillard S, Zhao X, Wu JT, Nicchitta CV, Yoshida M, Toft DO, Pratt WB and Yao TP: HDAC6 regulates Hsp90 acetylation and chaperone-dependent activation of glucocorticoid receptor. Mol Cell 18: 601-607, 2005.

60. Chen D, Sun Y, Wei Y, Zhang P, Rezaeian $\mathrm{AH}$, Teruya-Feldstein J, Gupta S, Liang H, Lin HK, Hung MC and Ma L: LIFR is a breast cancer metastasis suppressor upstream of the Hippo-YAP pathway and a prognostic marker. Nat Med 18: 1511-1517, 2012.

61. Wyckoff JB, Pinner SE, Gschmeissner S, Condeelis JS and Sahai E: ROCK- and myosin-dependent matrix deformation enables protease-independent tumor-cell invasion in vivo. Curr Biol 16: 1515-1523, 2006.

62. Garmpis N, Damaskos C, Garmpi A, Kalampokas E, Kalampokas T, Spartalis E, Daskalopoulou A, Valsami S, Kontos M, Nonni A, et al: Histone deacetylases as new therapeutic targets in triple-negative breast cancer: Progress and promises. Cancer Genomics Proteomics 14: 299-313, 2017.

63. Park Y, Lee KS, Park SY, Kim JH, Kang EY, Kim SW, Eom KY, Kim JS and Kim IA: Potential prognostic value of histone deacetylase 6 and acetylated heat-shock protein 90 in early-stage breast cancer. J Breast Cancer 18: 249-255, 2015.

64. Kekatpure VD, Dannenberg AJ and Subbaramaiah K: HDAC6 modulates Hsp90 chaperone activity and regulates activation of aryl hydrocarbon receptor signaling. J Biol Chem 284: 7436-7445, 2009.

65. Li D, Marchenko ND and Moll UM: SAHA shows preferential cytotoxicity in mutant $\mathrm{p} 53$ cancer cells by destabilizing mutant p53 through inhibition of the HDAC6-Hsp90 chaperone axis. Cell Death Differ 18: 1904-1913, 2011.

66. Dietz KC and Casaccia P: HDAC inhibitors and neurodegeneration: At the edge between protection and damage. Pharmacol Res 62: 11-17, 2010.

67. Dokmanovic M, Clarke C and Marks PA: Histone deacetylase inhibitors: Overview and perspectives. Mol Cancer Res 5 : 981-989, 2007.

68. Marks PA, Richon VM and Rifkind RA: Histone deacetylase inhibitors: Inducers of differentiation or apoptosis of transformed cells. J Natl Cancer Inst 92: 1210-1216, 2000.

69. Kushner MH, Ory V, Graham GT, Sharif GM, Kietzman WB, Thevissen S, Yuan M, Schmidt MO, Wellstein A and Riegel AT: Loss of ANCO1 repression at AIB1/YAP targets drives breast cancer progression. EMBO Rep 21: e48741, 2020.

70. Wang L, Wang C, Tao Z, Zhao L, Zhu Z, Wu W, He Y, Chen H, Zheng B, Huang X, et al: Curcumin derivative WZ35 inhibits tumor cell growth via ROS-YAP-JNK signaling pathway in breast cancer. J Exp Clin Cancer Res 38: 460, 2019.

71. Chen W, Bai Y, Patel C and Geng F: Autophagy promotes triple negative breast cancer metastasis via YAP nuclear localization. Biochem Biophys Res Commun 520: 263-268, 2019.

72. Wang X, Su L and Ou Q: Yes-associated protein promotes tumour development in luminal epithelial derived breast cancer. Eur J Cancer 48: 1227-1234, 2012
73. Overholtzer M, Zhang J, Smolen GA, Muir B, Li W, Sgroi DC, Deng CX, Brugge JS and Haber DA: Transforming properties of YAP, a candidate oncogene on the chromosome 11q22 amplicon. Proc Natl Acad Sci USA 103: 12405-12410, 2006.

74. Liu X, Li H, Rajurkar M, Li Q, Cotton JL, Ou J, Zhu LJ, Goel HL, Mercurio AM, Park JS, et al: Tead and AP1 coordinate transcription and motility. Cell Rep 14: 1169-1180, 2016.

75. Gaggioli C, Hooper S, Hidalgo-Carcedo C, Grosse R, Marshall JF, Harrington K and Sahai E: Fibroblast-led collective invasion of carcinoma cells with differing roles for RhoGTPases in leading and following cells. Nat Cell Biol 9: 1392-1400, 2007.

76. Schlienger S, Campbell S and Claing A: ARF1 regulates the Rho/MLC pathway to control EGF-dependent breast cancer cell invasion. Mol Biol Cell 25: 17-29, 2014.

77. Zanconato F, Forcato M, Battilana G, Azzolin L, Quaranta E, Bodega B, Rosato A, Bicciato S, Cordenonsi M and Piccolo S: Genome-wide association between YAP/TAZ/TEAD and AP-1 at enhancers drives oncogenic growth. Nat Cell Biol 17: $1218-1227,2015$

78. Lamar JM, Stern P, Liu H, Schindler JW, Jiang ZG and Hynes RO: The Hippo pathway target, YAP, promotes metastasis through its TEAD-interaction domain. Proc Natl Acad Sci USA 109: E2441-E2450, 2012

79. Delve E, Co V, Regmi SC, Parreno J, Schmidt TA and Kandel RA: YAP/TAZ regulates the expression of proteoglycan 4 and tenascin $\mathrm{C}$ in superficial-zone chondrocytes. Eur Cell Mater 39: 48-64, 2020.

80. Faião-Flores F, Emmons MF, Durante MA, Kinose F, Saha B, Fang B, Koomen JM, Chellappan SP, Maria-Engler SS, Rix U, et al: HDAC inhibition enhances the in vivo efficacy of MEK inhibitor therapy in uveal melanoma. Clin Cancer Res 25: 5686-5701, 2019.

81. Han H, Yang B, Nakaoka HJ, Yang J, Zhao Y, Le Nguyen K, Bishara AT, Mandalia TK and Wang W: Hippo signaling dysfunction induces cancer cell addiction to YAP. Oncogene 37: 6414-6424, 2018.

82. Liu Y, Xing H, Jiang X, Chen Y, Huang M and Yu S: Network pharmacology-based preventive effect of XZF on cutaneous toxicities induced by EGFR inhibitor. Biomed Pharmacother 123: 109755,2020

83. Wang X, Li XD, Fu Z, Zhou Y, Huang X and Jiang X: Long noncoding RNA LINC00473/miR1955p promotes glioma progression via YAP1TEAD1Hippo signaling. Int J Oncol 56: 508-521, 2020

84. Zucchini C, Manara MC, Cristalli C, Carrabotta M, Greco S, Pinca RS, Ferrari C, Landuzzi L, Pasello M, Lollini PL, et al: ROCK2 deprivation leads to the inhibition of tumor growth and metastatic potential in osteosarcoma cells through the modulation of YAP activity. J Exp Clin Cancer Res 38: 503, 2019.

85. Renda I, Bianchi S, Vezzosi V, Nori J, Vanzi E, Tavella K and Susini T: Expression of FGD3 gene as prognostic factor in young breast cancer patients. Sci Rep 9: 15204, 2019.

86. Shuai Y, Ma Z, Liu W, Yu T, Yan C, Jiang H, Tian S, Xu T and Shu Y: TEAD4 modulated LncRNA MNX1-AS1 contributes to gastric cancer progression partly through suppressing BTG2 and activating BCL2. Mol Cancer 19: 6, 2020.

87. Wang J, Zou Y, Wu X, Chen M, Zhang S, Lu X and Wang Q: DACH1 inhibits glioma invasion and tumor growth via the Wnt/catenin pathway. Onco Targets Ther 11: 5853-5863, 2018.

(i) $\odot$ This work is licensed under a Creative Commons Attribution-NonCommercial-NoDerivatives 4.0 International (CC BY-NC-ND 4.0) License. 